\title{
Nuclear receptors: coactivators, corepressors and chromatin remodeling in the control of transcription
}

\section{T N Collingwood, F D Urnov and A P Wolffe}

Laboratory of Molecular Embryology, National Institute of Child Health and Human Development, National Institutes of Health, Building 18T, Room 106, Bethesda, Maryland 20892-5431, USA

(Requests for offprints should be addressed to A P Wolffe; Email: awlme@helix.nih.gov)

\begin{abstract}
A contemporary view of hormone action at the transcriptional level requires knowledge of the transcription factors including the hormone receptor that may bind to promoters or enhancers, together with the chromosomal context within which these regulatory proteins function. Nuclear receptors provide the best examples of transcriptional control through the targeted recruitment of large protein complexes that modify chromosomal components and reversibly stabilize or destabilize chromatin. Ligand-dependent recruitment of transcriptional coactivators destabilizes chromatin by
\end{abstract}

mechanisms including histone acetylation and contacts with the basal transcriptional machinery. In contrast, the recruitment of corepressors in the absence of ligand or in the presence of hormone antagonists serves to stabilize chromatin by the targeting of histone deacetylases. Both activation and repression require the action of other chromatin remodeling engines of the switch $2 /$ sucrose nonfermentable 2 (SWI2/SNF2) class. Here we summarize this information and integrate hormone action into a chromatin context.

Fournal of Molecular Endocrinology (1999) 23, 255-275

\section{INTRODUCTION}

The nuclear hormone receptors provide transcription research with a clear example of how the reversible modification of chromatin structure can contribute to the control of gene expression. Remarkable progress in the definition of intermediary protein complexes that activate or repress transcription has allowed common themes in transcriptional control by a wide variety of receptors to emerge. The roles of these coactivators and corepressors in mediating the activities of nuclear receptors within chromatin is a key element of contemporary molecular endocrinology. The beststudied receptors in this regard are those for the glucocorticoid and thyroid hormones.

The glucocorticoid receptor recognizes response elements within nucleosomes as a first step towards a finely orchestrated rearrangement of histoneDNA contacts concomitant with the assembly of a functional transcription complex. The determinants of chromatin remodeling and the molecular machines that carry it out are now understood in considerable detail. Likewise, the thyroid hormone receptor recognizes nucleosomal DNA and utilizes chromatin to regulate transcription. However, in this case the receptor exerts a dual function. In the absence of ligand, the thyroid hormone receptor recruits a corepressor complex that stabilizes chromatin structure. Upon addition of hormone the receptor releases this repressive complex, and recruits coactivators that destabilize chromatin and promote transcription.

This review illustrates the role of chromatin, coactivators and corepressors in gene control as orchestrated by the glucocorticoid and thyroid hormone receptors.

\section{COACTIVATORS AND COREPRESSORS}

\section{Coactivators}

The interplay of distinct nuclear receptor responsive transcription pathways has been recognized for 
TABLE 1. Yeast SWI/SNF complexes and mammalian BRG1/BAF complexes: structural and functional similarities (Kennison \& Tamkun 1988, Tamkun et al. 1992, Elfring et al. 1998)

Components

\begin{tabular}{lll}
\hline SWI/SNF & & BRG1/BAF \\
\cline { 1 - 1 } SWI 1 & & BAF 250 \\
SWI 2 & & BRG1 \\
SWI 3 & & BAF 155/170 \\
SWP 73 & & BAF 60 \\
SWP 61 & & BAF 53 \\
SWP 59 & & Actin
\end{tabular}

Structure-function

Contain LXXLL motifs - may be targeted by nuclear receptors

DNA-dependent ATPase engine for chromatin disruption

Similar sequence - no known function

Similar sequence - no known function

Actin-like protein - important for association with the nucleus

Actin or actin-like protein - important for association with the nucleus

SWP, switch associated protein.

some time (Bocquel et al. 1989, Meyer et al. 1989). The capacity for the activation of transcription by one nuclear receptor to compromise the transcriptional response dependent on a second receptor implied that shared components of transcriptional machinery were involved. An explanation for this transcriptional interference became apparent with the discovery of shared coactivator proteins that facilitated communication between nuclear receptors, the basal transcriptional machinery and the chromatin environment (reviewed by Torchia et al. 1998).

Coactivators can be divided into two general classes: members of the switch/sucrose nonfermentable (SWI/SNF) family of proteins and members of the histone acetyltransferase family. Both classes of coactivators have the capacity to modify the chromatin environment facilitating transcription indirectly by alleviating the repressive effects of histone-DNA contacts. They can also potentially influence the activity of the basal transcriptional machinery directly through proteinprotein contacts. The SWI/SNF family of proteins were first characterized as regulators of gene expression in the yeast Saccharomyces cerevisiae (Neigeborn \& Carlson 1984, Stern et al. 1984). Ligand-dependent transcriptional activation by the glucocorticoid receptor (GR) in yeast was facilitated by several SWI gene products such as SwI1p, SwI2p and SwI3p (Yoshinaga et al. 1992). These are all components of a large SWI/SNF chromatin remodeling complex (Peterson et al. 1994). The targeting of the SWI/SNF complex to the GR might be explained by the presence of receptor binding motifs (LXXLL) in SWI1p (Heery et al. 1997). The Drosophila gene Brahma (Brm) encodes a protein highly similar in sequence to SwI2p.
Brahma is required for the developmental control of several of the homeotic genes that define segmental identity in the Drosophila embryo. It remains to be determined whether Brahma is required for transcriptional regulation by the several members of the nuclear receptor superfamily found in Drosophila. The Brahma protein is assembled into a large complex that includes several other proteins that are homologous to the yeast SWI/SNF complex (Papoulas et al. 1998). The equivalent mammalian complex has a similar subunit composition in which the SWI2p homologue is represented by the protein encoded by Brahma-related gene 1 (BRG1) (Table 1; Zhao et al. 1998). Human BRG1 and related proteins interact with nuclear receptors in mammalian cells (Muchardt \& Yaniv 1993, Chiba et al. 1994). These interactions have functional consequences for the remodeling of chromatin targeted by the glucocorticoid receptor (Fryer \& Archer 1998).

Histone acetyltransferase coactivators (reviewed by Torchia et al. 1998) were identified initially on the basis of their interaction with the ligand binding domain of a variety of nuclear receptors in the presence of cognate receptor ligands, with subsequent studies revealing their histone acetyltransferase (HAT) activity (Spencer et al. 1997). Perhaps the best characterized group of HAT coactivators is the p160 family, in which multiple variations have been isolated which share a striking homology, the structural features of which are typically represented by steroid receptor coactivator-1a (SRC-1a) in Fig. 1a. To date, three distinct members of the p160 family have been isolated that exist as multiple splice variants including SRC-1/NCoA-1, TIF2/ GRIP1/NCoA-2, and p/CIP/ACTR/RAC3/AIB1/ TRAM-1 (Onate et al. 1995, Hong et al. 1996, 
(a)

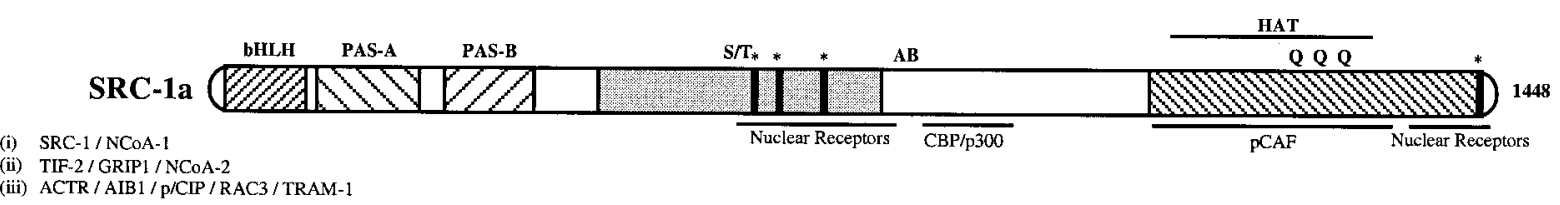

(b)

(ii) TIF-2 / GRIP1 / NCOA-2

(iii) $\mathrm{ACTR} / \mathrm{AIB} 1 / \mathrm{p} / \mathrm{CIP} / \mathrm{RAC} 3$ / TRAM-1

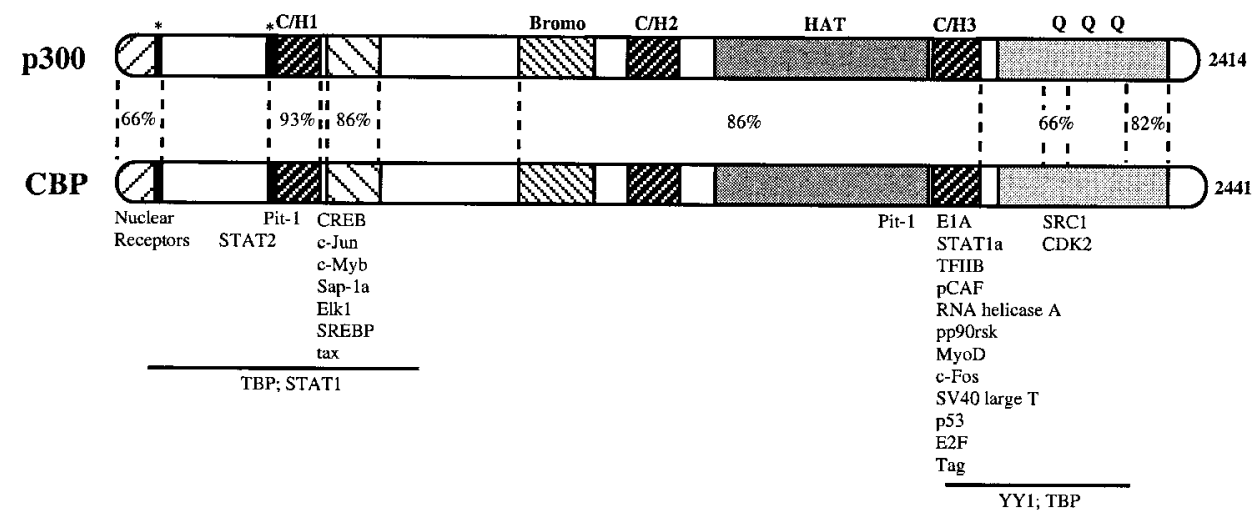

(c)

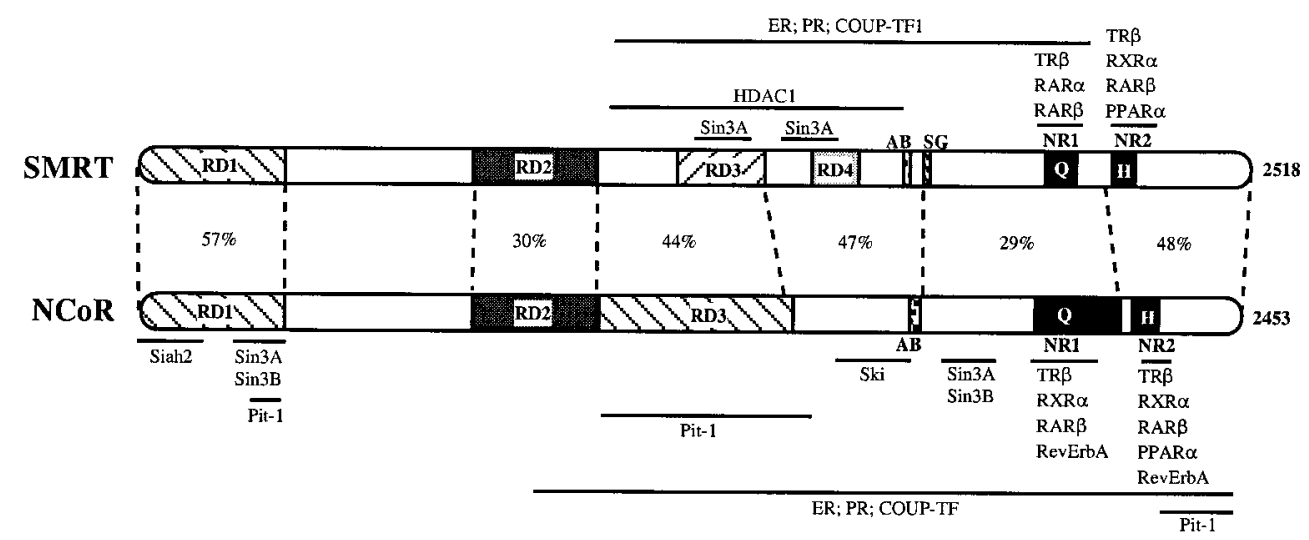

(d)

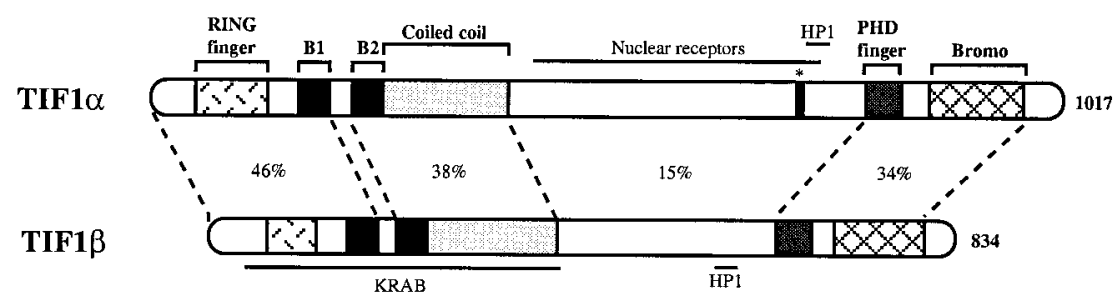

FIGURE 1. Structural features of nuclear receptor coactivators and corepressors. Conserved motifs or regions important for enzymatic activity are shown in bold text. Factors known to interact with these proteins are shown in plain text. Homology is represented as identity. (a) The structure of SRC-1a is representative of a class of highly homologous coactivators. These are divided into three subgroups (i, ii, iii) based on more stringent homology. Asterisks denote LXXLL motifs. bHLH, basic helix-loop-helix; PAS, period/aryl hydrocarbon receptor/single minded; S/T, serine/threonine rich; $\mathrm{AB}$, acidic basic; HAT, histone acetyltransferase activity; QQQ, glutamine rich. (b) p300 vs CBP. C/H, cysteine rich; Bromo, bromodomain. (c) SMRT vs NCoR. RD, repression domain; NR, nuclear receptor interacting domain; SG, serine/glycine rich; H, $\alpha$-helical. (d) TIF1 $\alpha$ vs TIF1 $\beta$. B, B box fingers. 
TABLE 2. Nuclear receptor cofactors

\begin{tabular}{|c|c|c|}
\hline & $\begin{array}{l}\text { Nuclear receptor target } \\
\text { in vitro }\end{array}$ & Function \\
\hline $\begin{array}{l}\text { Protein } \\
\text { Coactivators } \\
\text { SRC-1, NCoA-1 }\end{array}$ & ER, GR, PR, TR, RXR & $\begin{array}{l}\text { Acetyltransferase } \\
\text { Interacts with CBP }\end{array}$ \\
\hline TIF2, GRIP1, NCoA2 & ER, AR, GR, PR & Interacts with $\mathrm{CBP}$ \\
\hline P/CIP, ACTR, RAC3 & ER, PR, TR, RAR, & Acetyltransferase \\
\hline AIB1, TRAM1 & RXR, VDR & Interacts with $\mathrm{CBP}, \mathrm{PCAF}$ \\
\hline PCAF & RAR, RXR & $\begin{array}{l}\text { Acetyltransferase } \\
\text { Interacts with p } 300 / \mathrm{CBP}\end{array}$ \\
\hline $\mathrm{P} 300 / \mathrm{CBP}$ & ER, TR, RAR, RXR & $\begin{array}{l}\text { Acetyltransferase } \\
\text { Interacts with SRC-1, PCAF }\end{array}$ \\
\hline $\begin{array}{l}\text { Corepressors } \\
\text { NCoR, SMRT }\end{array}$ & $\begin{array}{l}\text { TR, RAR, RXR } \\
\text { ER+ hormone antagonist } \\
\text { PR+hormone antagonist }\end{array}$ & $\begin{array}{l}\text { Interacts with SIN3 to recruit } \\
\text { histone deacetylase }\end{array}$ \\
\hline TIF1 $\alpha$, TIF1 $\beta$ & RAR & $\begin{array}{l}\text { Interacts with HP1 and } \\
\text { histone deacetylase }\end{array}$ \\
\hline
\end{tabular}

Kamei et al. 1996, Voegel et al. 1996, Anzick et al. 1997, Chen et al. 1997, Li et al. 1997, Takeshita et al. 1997, Torchia et al. 1997, summarized in Table 2). SRC-1 also recruits other acetyltransferases including $\mathrm{p} 300$, cyclic AMP response element (CREB) binding protein (CBP) and $\mathrm{p} 300$ CBP associated factor (PCAF) (Hanstein et al. 1996, Kamei et al. 1996, Yao et al. 1996, Voegel et al. 1998, summarized in Table 2). Interestingly, studies with retinoic acid receptor (RAR) have found that acetyltransferase domain of SRC-1 is not essential for transcriptional activation but that the corresponding domain of PCAF is required (Korzus et al. 1998).

p300 and CBP are highly related histone acetyltransferases (Fig. 1b) that interact with SRC-1, but also bind independently to nuclear hormone receptors in a ligand-dependent manner (Chakravarti et al. 1996). p300 and CBP can enhance ligand-dependent transcriptional activation in synergy with SRC-1 (Smith et al. 1996). p300, CBP and SRC-1 also interact independently with PCAF (Yang et al. 1996, Torchia et al. 1997, Blanco et al. 1998) leading to the concept that a very large histone acetyltransferase factory might be assembled in the vicinity of a ligand-bound receptor (Wade et al. 1997). Biochemical fractionation indicates that diverse acetyltransferases exist as distinct subcomplexes in the cell (McKenna et al.
1998). Analysis of nuclear receptor coactivators has revealed the existence of multiple highly conserved amphipathic 'LXXLL' helical motifs (Heery et al. 1997). These motifs play an important role in mediating the interaction between coactivators and receptors by associating with critical residues in a coactivator interface region of the receptor ligand binding domain. Mutation of these residues abrogates both coactivator recruitment and transactivation (Collingwood et al. 1997, 1998, Feng et al. 1998, Nolte et al. 1998). Nolte and colleagues also showed that a single peptide from SRC-1 could associate with a liganded PPAR $\gamma$ (peroxisome proliferator activated receptor) homodimer and that each of two adjacent LXXLL motifs made identical contacts with both subunits of the homodimer (Nolte et al. 1998). These motifs are central to determining the specificity of the receptorcoactivator interaction since studies on the three core LXXLL motifs in SRC-1 showed that whereas a single motif was necessary for activation of the estrogen receptor (ER), different combinations of two appropriately spaced motifs are required for activation of thyroid hormone (TR), retinoic acid (RAR), progesterone (PR) and peroxisome proliferator activated (PPAR $\gamma$ ) receptors (McInerney et al. 1998). Residues adjacent to the motifs are also important for determining the receptor specificity of interaction and it is suggested that the common 
structural elements facilitate regulation through multiple coactivators, while side chains at the interface impart specificity (Darimont et al. 1998). In addition, LXXLL motifs have been shown to be important in mediating the interaction between SRC-1 and CBP/p300 (McInerney et al. 1998), as well as between a $270 \mathrm{kDa}$ protein related to $\mathrm{CBP} / \mathrm{p} 300$ and components of the human SWI/ SNF complex (Dallas et al. 1998). This combinatorial flexibility might contribute both to the specificity of transcriptional activation by particular receptors in certain cell types and to the interdependence of regulatory pathways where different receptors require a distinct subcomplex of acetyltransferases. This indicates that the two general classes of coactivator might act in concert to regulate transcription. Exactly how this might be achieved will be discussed later.

\section{Corepressors}

Just as coactivators facilitate the activation of transcription by ligand-bound receptors, corepressors can help repress transcription dependent on the presence of certain nuclear receptors such as RAR and TR in the absence of ligand or for ER in the presence of antagonists. Since many components of chromatin can non-specifically repress transcription, an important component in the activity of corepressors is their targeting to the receptor. Early experiments that suggested the existence of corepressors came from 'repressioninterference' assays where TR-mediated repression was reduced in the presence of excess unliganded RAR or v-ErbA (Baniahmad et al. 1992). Subsequent experiments have identified two potential classes of corepressors: the nuclear hormone receptor corepressor ( $\mathrm{NCoR})$ and silencing mediator of retinoid and thyroid receptors (SMRT) proteins for the major family (Fig. 1c; Chen \& Evans 1995, Horlein et al. 1995, Kurokawa et al. 1995, Zamir et al. 1997, Ordentlich et al. 1999) and the transcription intermediary factor-1 (TIF1) proteins as the other family (Le Douarin et al. 1995, 1996, Vom Baur et al. 1996). Like the coactivators, the corepressors appears to exert significant functions through the modification of chromatin. Both classes of corepressors function to recruit histone deacetylase to the vicinity of the receptor.

The NCoR and SMRT corepressors interact with the unliganded TR or RAR when associated with their retinoid $\mathrm{X}$ receptor (RXR) heterodimeric partner (Chen \& Evans 1995, Horlein et al. 1995, Kurokawa et al. 1995, Lee et al. 1995, Jackson et al. 1997, Smith et al. 1997, Lavinsky et al. 1998).
Studies have defined a region, termed the CoR box, in the hinge between the receptor DNA binding domain (DBD) and ligand binding domain (LBD) that is critical for association with corepressors (Horlein et al. 1995). Subsequent work indicates that the extreme carboxy-terminus is also important, particularly in facilitating corepressor release as a result of hormone-induced allosteric changes (Baniahmad et al. 1995, Lin et al. 1997). A role for hormone in effecting this structural transition is highlighted by the observation that a highly mutated form of the chicken TR, the oncoprotein v-ErbA, fails to bind hormone, is continuously associated with SMRT (Chen \& Evans 1995) or $\mathrm{NCoR}$ (Horlein et al. 1995) and is thought to act as a constitutive transcriptional repressor. The ER can also bind the NCoR and SMRT corepressors in the presence of antagonists such as tamoxifen and RU486 (Laherty et al. 1998, Lavinsky et al. 1998). NCoR and SMRT are components of a complex that contains SIN3 and histone deacetylase (Alland et al. 1997, Heinzel et al. 1997, Nagy et al. 1997). SIN3, a protein containing four paired amphipathic helical domains, interacts with a diverse collection of nuclear proteins. The main function of SIN3 appears to be to serve as an intermediary between the receptor and histone deacetylase itself (Wong \& Privalsky 1998).

The TIF1 $\alpha$ and $\beta$ family of corepressors (Fig. 1d) were initially identified by the capacity of TIF1 $\alpha$ to interact with the ligand-binding domain of the RAR in the presence of hormone (Le Douarin et al. 1995, 1996). This would initially suggest that they should activate transcription, however subsequent work has established that the highly related TIF1 $\beta$ corepressor binds to the KRAB repression domain found in many zinc-finger proteins and with heterochromatin protein (HP1). These observations led to the proposal that nuclear receptors might target the assembly of a microdomain of heterochromatin (Le Douarin et al. 1995). Alternative proposals from these workers include the possibility that the TIF1 proteins might be involved in ligand-dependent transcriptional repression or in promoting the conversion of an inactive heterochromatin-like structure to an active chromatin structure (Le Douarin et al. 1998). How this latter possibility might be achieved is so far unclear. Subsequent work has indicated that KRAB and TIF $\beta$ repression also depends on the recruitment of deacetylase ( $R$ Kimmel \& A P Wolffe, unpublished observations). Thus both classes of corepressors will recruit histone deacetylase. The consequences of the local concentration of deacetylase enzyme will be to stabilize chromatin structure and repress transcription. 
TABLE 3. Glossary of chromatin terms

\section{Explanation}

Term

Nucleosome

Histone

Chromatin fiber

Superhelix

Dyad axis

Open chromatin

Closed chromatin
Nucleoprotein complex of two molecules of each of the four core histones $\mathrm{H} 2 \mathrm{~A}, \mathrm{H} 2 \mathrm{~B}, \mathrm{H} 3$ and $\mathrm{H} 4$, one molecule of linker histone $\mathrm{H} 1$ and $166-200 \mathrm{bp}$ of DNA.

Small basic protein with a $\mathrm{C}$-terminal domain involved in histone-histone interaction and an N-terminal 'tail' domain that projects outside the nucleosome.

Compact structure about $30 \mathrm{~nm}$ in diameter that is assembled from nucleosome arrays.

A helix formed by a strand that is itself a helix, as in DNA.

The point in the nucleosome that forms an axis of symmetry.

Chromatin that contains DNA that is accessible to nucleases and the transcription machinery.

Chromatin that is inaccessible to nucleases and the transcriptional machinery and is generally transcriptionally silent.

\section{CHROMATIN AND THE TRANSCRIPTIONAL MACHINERY}

\section{Chromatin modification and disruption}

Chromatin is composed of a simple repetitive structural element known as the nucleosome, which has the capacity to self-associate into a higher-order structure described as the chromatin fiber (see Table 3 for a glossary of terms). The individual chromatin fibers can also self-associate into the basic matrix of chromosomes (Fig. 2, Wolffe 1998). These self-association events are controlled by the modification state of the histones (Tse et al. 1998). Acetylation of the core histones destabilizes chromatin folding at all levels. A major consequence of this destabilization is that histone acetylation facilitates transcription factor access to DNA and transcription itself (Lee et al. 1993, Lefebvre et al. 1998, Ura et al. 1997, Nightingale et al. 1998, Tse et al. 1998). An effect of acetylating the basic $\mathrm{N}$-terminal tail domains of the core histones is to reduce the stability of electrostatic interactions between the tail domains and both the acidic phosphodiester backbone of DNA and the acidic domains of other proteins present in nucleosomes and other chromatin fibers (Hong et al. 1993, Luger et al. 1997, Tse et al. 1998). There may also be consequences for both histone secondary structure and interactions with non-histone proteins following acetylation (Hansen et al. 1998).

Every nucleosome in a typical animal cell consists of two molecules of each of the four core histones, $\mathrm{H} 2 \mathrm{~A}, \mathrm{H} 2 \mathrm{~B}, \mathrm{H} 3$ and $\mathrm{H} 4$, about $180 \mathrm{bp}$ of DNA and a single molecule of a linker histone H1. Each histone has two domains, an N-terminal tail that faces solution at the outer surface of the nucleosome and a C-terminal histone fold domain that is involved in wrapping DNA (Arents et al. 1991, Luger et al. 1997). In S. cerevisae, mutations of the $\mathrm{N}$-terminal tails that reduce basicity eliminate the requirement for histone acetyltransferases to activate transcription (Zhang et al. 1998). In contrast, mutations in the histone fold domains eliminate requirements for the SWI/SNF coactivators (Kruger et al. 1995). These mutations that influence

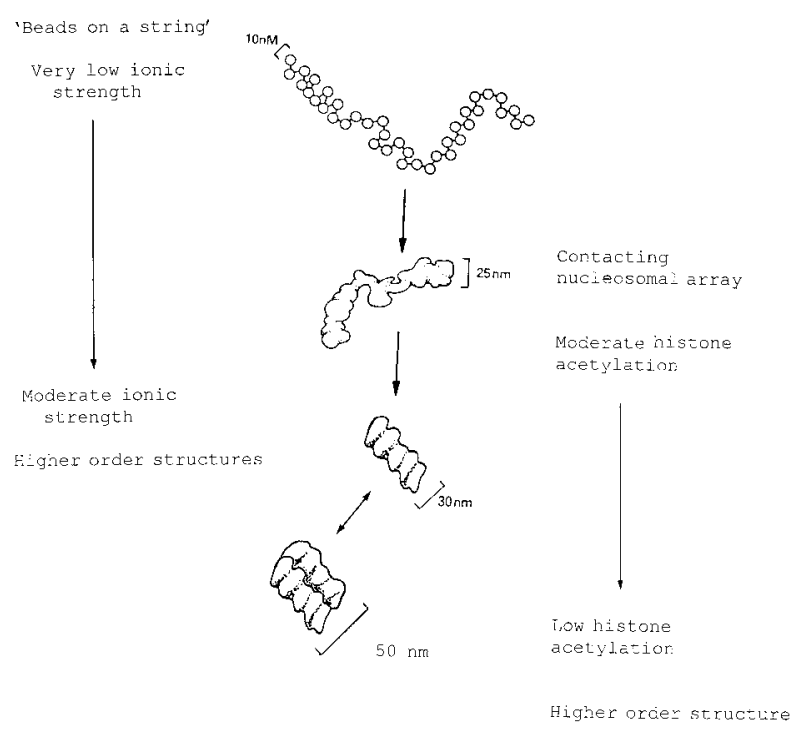

FIGURE 2. Folding of chromatin as visualized in the electron microscope and assayed using the analytical ultracentrifuge. As ionic strength increases chromatin changes from a beads-on-a-string configuration to a array in which nucleosomes make direct physical contacts, to a flat fiber, $30 \mathrm{~nm}$ in diameter which can self-associate to form higher-order structures. These structural transitions are impeded by increases in the acetylation level of the core histones (Tse et al. 1998). 
the need for the SWI/SNF complex destabilize the nucleosome (Kurumizaka \& Wolffe 1997, Weschser et al. 1997). DNA is still wrapped around the core histones in a destabilized nucleosome, but the double helix is much less constrained in terms of which surface faces solution compared with being in contact with the histones. Thus genetic and structural data combine to implicate chromatin modification and disruption as major functions for both the histone acetyltransferase and the SWI/ SNF coactivators.

Linker histones are also targets for posttranslational modification, in this case by phosphorylation. Like acetylation of the core histones, phosphorylation of $\mathrm{H} 1$ weakens interaction of the protein with DNA. Histone H1 consists of a globular central domain flanked by lysine-rich highly basic amino terminal and carboxyl terminal tails (Wolffe et al. 1997). The globular domain interacts with DNA in contact with the core histones (Pruss et al. 1996), whereas the tails bind to linker DNA. Phosphorylation of the histone H1 tails occurs on serine residues predominantly at conserved SPKK motifs present in the charged tail regions. In addition to weakening the electrostatic interactions with DNA, phosphorylation of $\mathrm{H} 1$ will also destabilize $\alpha$-helical structures present in the linker histone tail domains (Clark et al. 1988, Szilak et al. 1997) further reducing the stability of association with chromatin (Hill et al. 1991).

We will see that core histone acetylation, linker histone phosphorylation and the SWI/SNF complex mediated disruption of chromatin can all contribute to gene control by coactivators and corepressors. However, to understand the significance of these structural transitions we first have to describe why chromatin modification and disruption are important for transcription control.

\section{Chromatin and transcription factor access to DNA}

Wrapping DNA around the core histones in a nucleosome creates severe steric impediments for transcription factors that need to gain access to specific recognition sequences. One side of the double helix is in association with the histones with the adjacent turn of DNA in the nucleosome also limiting accessibility. In addition, DNA is severely distorted into two shallow superhelical turns of $80 \mathrm{bp}$ each, this will require a protein that binds to DNA on the outer face of the double helix in the continued presence of the core histones to distort itself around this surface (Fig. 3; Wolffe 1998). For the vast majority of transcription factors, the assembly of their recognition elements into
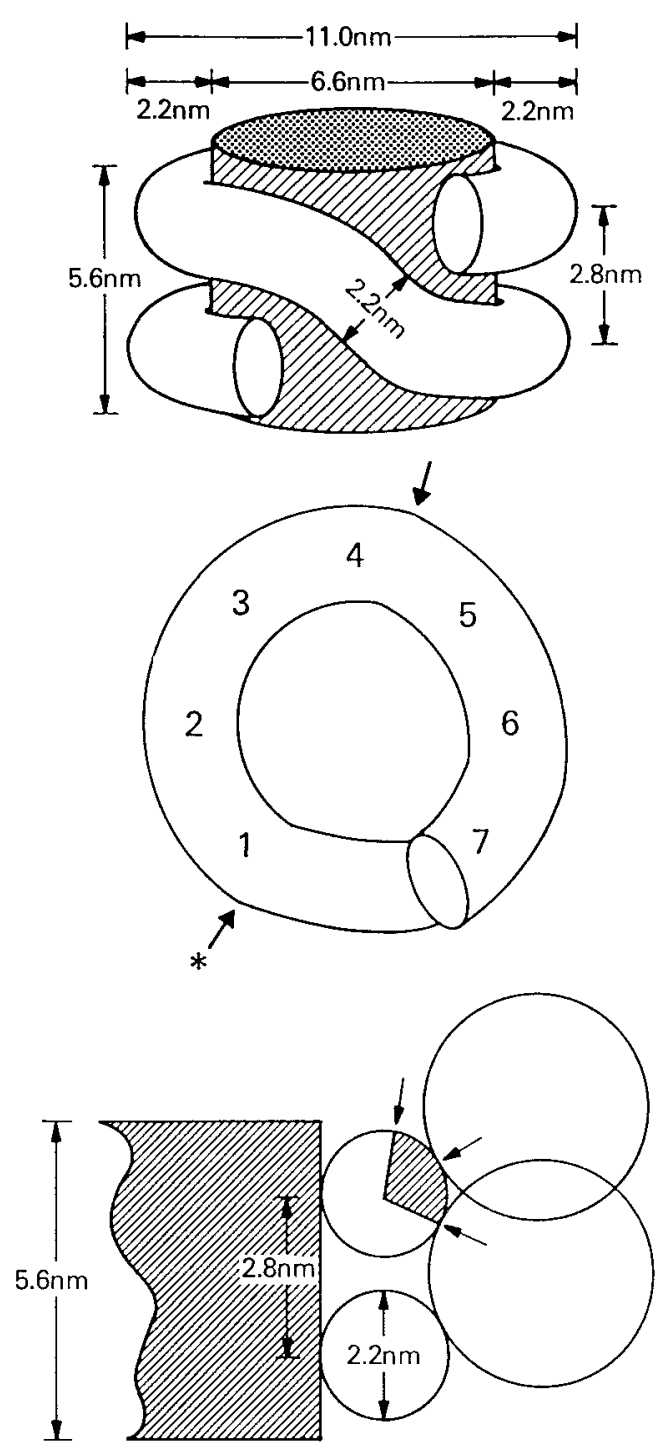

FIGURE 3. Impediments to transcription factor access in the nucleosome. The nucleosome is shown with the histones as a hatched cylinder and DNA as the open tube. The top panel shows an image overlooking the center of nucleosomal DNA, at which point the DNA superhelix rises very steeply. The middle panel shows the path of a single turn of DNA in the nucleosome. Numbers refer to turns of the double helix away from the dyad axis. The arrows represent the positions of more severe DNA distortion. The asterisk marks the approximate position of base pair unstacking detected by singlet oxygen and hydroxyl radical cleavage. The lower panel illustrates the limited access of transcription factors to DNA in the nucleosome. A cross-section of one side of the nucleosome is shown. Transcription factor (large circle) access to DNA (small circle) is restricted by the histone core (hatched box) and the adjacent turn of DNA. The only freely accessible region of the double helix is the hatched segment marked by arrows. 


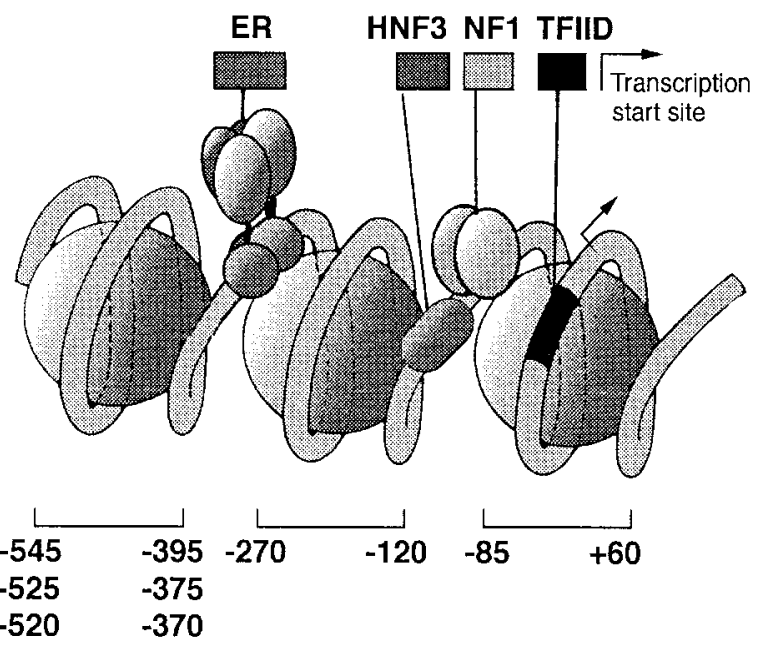

FIGURE 4. A model for the nucleoprotein organization of the Xenopus vitellogenin B1 promoter. The organization of three nucleosomes relative to the start site of transcription $(+1)$ is shown (Schild et al. 1993, D Robyr, A Gegonne, A P Wolffe \& W Wahli, unpublished) together with the binding sites for ER, hepatocyte nuclear factor 3 (HNF3), NF1 and TFIID as illustrated.

nucleosomes reduces their binding affinity by two to three orders of magnitude. The basal transcriptional machinery has special problems in gaining access to nucleosomal DNA because of the severe distortion in the path of DNA that occurs on association of TBP (TATA-box binding proteins). The assembly of a TATA box into a nucleosome prevents TBP binding independent of the position of the sequence relative to the histone surface (Imbalzano et al. 1994, Godde et al. 1995). In vivo the assembly of a TATA box into a nucleosome is a very efficient mechanism to repress transcription (Patterton \& Simpson 1994, Li et al. 1998). Thus nucleosomes must be disrupted over the TATA box in order for the basal transcriptional machinery to function effectively. Even once the basal transcriptional machinery has gained access to DNA and recruited RNA polymerase, the elongation of the polymerase can be impeded by chromatin (Morse 1989, Hansen \& Wolffe 1992, 1994). Both histone acetylation and the activity of SWI/SNF chromatin remodeling complexes can facilitate the processivity of RNA polymerase through chromatin (Brown et al. 1996, Ura et al. 1997).

A limited number of specialized transcriptional regulators retain the capacity to bind to their recognition elements even when they are wrapped up into nucleosomes. These include the glucocorticoid receptor (GR) and the thyroid hormone receptor (TR). The association of these regulatory proteins within chromatin positions them ideally to control transcription through the targeted recruitment of enzyme complexes that modify histoneDNA interactions and remodel nucleosomes. The GR and TR are examples of regulatory factors that can bind to DNA when it is wrapped on the nucleosome surface. There are other examples of nuclear receptors binding to the linker DNA between nucleosomes. The estrogen receptor is one such case which binds to linker DNA in the Xenopus vitellogenin B1 promoter adjacent to a positioned nucleosome that activates transcription (Fig. 4; Schild et al. 1993). Thus chromatin assembly should not always be considered as invariably repressive.

\section{THE MOUSE MAMMARY TUMOR VIRUS LONG TERMINAL REPEAT AND TRANSCRIPTIONAL CONTROL BY GLUCOCORTICOID RECEPTOR TARGETED CHROMATIN REMODELING}

\section{Architectural considerations}

Pre-eminent among the systems exploited to understand the interrelationships between chromatin structure and transcription as determined by nuclear receptors is the regulation by glucocorticoids of transcription of the mouse mammary tumor virus (MMTV) long terminal repeat (LTR) (Zaret \& Yamamoto 1984). Hager and colleagues established that the MMTV LTR is incorporated into six positioned nucleosomes in both episomes and within a mouse chromosome. The positioned nucleosomes serve to prevent the basal transcriptional machinery associating with the promoter under normal circumstances, that is in the absence of glucocorticoids (Archer et al. 1992). Induction of transcription by glucocorticoids requires binding of the glucocorticoid receptor (GR) to the LTR, disruption of the local chromatin structure initiated by the GR binding to recognition sequences within nucleosomes, and the assembly of a transcription complex over the TATA box (Archer et al. 1989, 1992). Thus the following sequences of events occur on this promoter: an inducible transcription factor binds to the chromatin template, chromatin structure is rearranged facilitating access of other regulatory factors to sequences within the promoter, a transcription complex is assembled and transcription is activated.

Vigorous attempts have been made to reconstruct the transcriptional regulation and concomitant chromatin structural changes of the MMTV LTR in vitro. The GR appears to bind nucleosomal DNA 

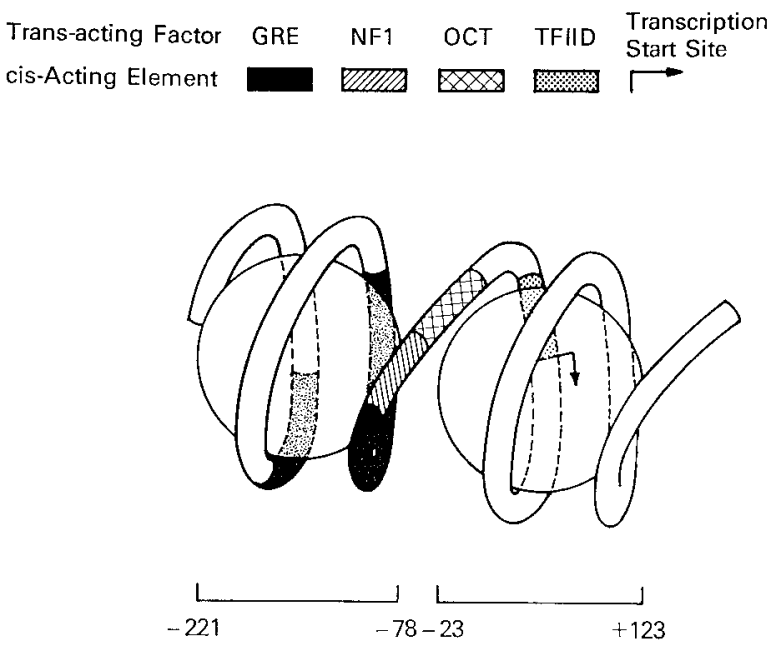

FIGURE 5. The organization of the MMTV LTR into a specific chromatin structure. Nucleosome positions and key recognition elements for trans-acting factors are indicated. The hooked arrow indicates the start site of transcription. Numbers indicate base pair positions of DNA incorporated into nucleosomes relative to the start site of transcription $(+1)$. OCT, octamer factor.

with only a slight reduction in affinity relative to naked DNA. This interaction is dependent on the precise position of the nucleosome and hence the translational position of the GR binding site within the nucleosome (Perlmann \& Wrange 1988, Pina et al. 1990a,b, Archer et al. 1991). In vitro nucleosome positions compare favorably with those determined in vivo (Richard-Foy \& Hager 1987). However, although a predominant in vivo translational position exists for this nucleosome, a number of distinct translational positions can be detected (Fragoso et al. 1995). Detailed in vitro analysis suggests that these variant positions are dependent on the DNA sequence (Roberts et al. 1995). This heterogeneity in translational position appears to reflect nucleosome mobility (Meersseman et al. 1992, Ura et al. 1995). The DNA sequence containing the GR-binding sites has regions of intrinsic flexibility and curvature that direct the histones to bind it in a particular way (Pina et al. 1990a,b, Roberts et al. 1995). Two GR recognition elements (GREs) are separated by $92 \mathrm{bp}$ which places them together on one side of the nucleosome. This proximity might facilitate both the binding and subsequent activity of GR (Perlmann \& Wrange 1991). The display of DNA binding sites on the surface of the nucleosome might actually promote the formation of a functional transcription complex (Fig. 5; Truss et al. 1995, Chavez \& Beato 1997).
Experiments that compare the affinity of the GR for a recognition element as free DNA compared with one facing towards solution in the nucleosome at different translational positions, show that binding affinity is reduced 3 - to 11 -fold in the nucleosome ( $\mathrm{Li} \&$ Wrange 1993). This is a remarkably small reduction compared with the complete absence of binding when the recognition element is facing towards the histones ( $\mathrm{Li} \&$ Wrange 1995). This suggests that the key variable determining the accessibility of the GR to its recognition element within the nucleosome is not the translational position of the recognition element, but the rotational position of the DNA sequence with respect to the surface of the histones.

The GR is well suited to interact specifically with nucleosomal DNA. GR binds to DNA using a domain containing two zinc fingers: an $\alpha$-helix in one of the two fingers interacts with a short $6 \mathrm{bp}$ region in the major groove of the double helix, while the other finger is involved in protein-protein interaction (Luisi et al. 1991). The GR associates with DNA as a dimer. The second molecule of the receptor has similar interactions on the same side of the double helix, one helical turn away. Thus GR can bind to DNA on the one side exposed towards solution in the nucleosome, thereby circumventing steric interference by the histone core. Surprisingly, association of the GR with the nucleosome containing its binding site appears to have no effect on the integrity of the structure in vitro, unlike the apparent consequence in vivo. Binding of the other promoter-specific transcription factors (nuclear factor 1-NF1), which is facilitated by the GR in vivo, does not occur in vitro on nucleosomal templates (Blomquist et al. 1996, Candau et al. 1996). Importantly, the GR is now positioned within chromatin such that it can effectively recruit the molecular machines necessary to remodel the MMTV chromatin in order to facilitate transcription.

\section{Chromatin remodeling}

The key molecular machine that GR recruits to the MMTV LTR is the mammalian BRG1/BRG1 associated factor (BAF) chromatin remodeling complex (Fryer \& Archer 1998). The BRG1/BAF complex had been known for a while to facilitate transcriptional activation by the ligand-bound glucocorticoid receptor (Murchardt \& Yaniv 1993), but the mechanism of targeting had been obscure. Fryer and Archer (1998) found that recruitment of the BRG1/BAF complex to the glucocorticoid receptor in vivo is dependent on the presence of ligand. The physical interaction between the 
receptor and the BRG1/BAF complex in the presence of endogenous levels of GR and progesterone receptor (PR) was eliminated by addition of an antiprogestin drug, which also blocked chromatin remodeling and transcriptional activation directed by the glucocorticoid receptor on the MMTV LTR. Interestingly, the interaction of the GR with the histone acetyltransferase family of coactivators as represented by p300 and SRC-1 was unaffected by the antiprogestin drug. Thus Fryer and Archer suggest that the recruitment of the $\mathrm{BRG} 1 / \mathrm{BAF}$ complex is the key regulatory event at the MMTV LTR and that the histone acetyltransferases have a subsidiary role. However, Bartsch and colleagues have also found that moderate increases in histone acetylation dependent on addition of the deacetylase inhibitor Trichostatin A will activate the MMTV LTR and remodel its chromatin structure (Bartsch et al. 1996). It is interesting to note that while GR binding will modestly facilitate BRG1/BAF disruption of nucleosomal DNA in vitro (OstlundFarrants et al. 1997), histone acetylation alone does not induce a major unfolding of the chromatin infrastructure in vitro or in vivo (Bresnick et al. 1990, 1991). Thus these in vitro observations are largely consistent with in vivo data.

The remodeling of the MMTV LTR chromatin involves a number of physical changes including the removal of histone $\mathrm{H} 1$ from the linker DNA of nucleosomes including regulatory DNA (Bresnick et al. 1992) and a substantial increase in the accessibility of the DNA that is within the positioned nucleosomes to nucleases (Zaret \& Yamamoto 1984). The phosphorylation of histone $\mathrm{H} 1$ in response to ligand-bound GR is an essential component of transcriptional activation. Thus it is probable that the GR facilitates the activation and recruitment of a protein kinase to the MMTV LTR (Lee \& Archer 1998). The positioning of the nucleosomes is also likely to have an important role in the displacement of histone $\mathrm{H} 1$, since the linker region between the nucleosomes contains the binding sites for histone $\mathrm{H} 1, \mathrm{NF} 1$ and the octamer factor. It is possible that histone $\mathrm{H} 1$ and the transcription factors might compete for binding to this linker region. In any event the transcription factors NF1, the octamer factor and transcription factor IID (TFIID) that lie in the linker DNA and at the periphery of the positioned nucleosomes are recruited to their binding sites in this disrupted chromatin (Archer et al. 1992) and assemble an active transcription complex. Transcriptional activation by GR is only transient and after a few hours the basal transcription complex, NF1, octamer factor and GR are displaced from the MMTV LTR and their binding sites are reincorporated into the positioned nucleosomes and the promoter repressed (Lee \& Archer 1994). Histone H1 dephosphorylation might also have a role in the silencing of the MMTV LTR since prolonged glucocorticoid exposure leads to both events occurring simultaneously (Lee \& Archer 1998). Although the exact molecular mechanisms responsible for displacement of the transcription factors have not been determined, these results indicate that both transcription factor and histone complexes with promoters are likely to be dynamic.

\section{THE XENOPUS THYROID HORMONE RECEPTOR BA PROMOTER AND TRANSCRIPTIONAL CONTROL BY THYROID HORMONE RECEPTOR TARGETED CHROMATIN REMODELING}

One of the best studied examples of hormone action during vertebrate development, the involvement of thyroid hormone in amphibian metamorphosis (Brown et al. 1995, Tata 1996), also provides a useful paradigm for the utility of targeted chromatin modification in effecting transcriptional regulation by nuclear hormone receptors (Wong et al. 1995). We have focused on the gene for the $\beta$ isoform of the thyroid hormone receptor in the African clawed frog, Xenopus laevis (Shi et al. 1993). During Xenopus ontogeny, TR $\beta$ levels correlate positively with the titer of its cognate ligand (Yaoita \& Brown 1990). A simple mechanism to effect such coupling could be based on the direct regulation of the TR $\beta$ gene by TR, and would exploit the transcription silencing properties of unliganded TR as well as its robust function as a transcriptional activator when agonist-bound. Work from this laboratory described in the following section elaborates on the details of this mechanism and highlights the efficiency with which the receptor exploits the assembly of its target gene into chromatin to effect changes in TR $\beta$ mRNA levels.

\section{Architectural considerations}

The promoter of the TR $\beta$ gene contains several thyroid hormone receptor response elements (TREs), and one of which, located at ca +270 , is sufficient to confer the regulation by triiodothyronine (T3) on plasmid templates microinjected into oocytes (Ranjan et al. 1994, Wong et al. 1995), while the remaining TREs are likely involved in fine-tuning hormone responsiveness. We find that the DNA sequences within the first $500 \mathrm{bp}$ of the TR $\beta \mathrm{A}$ gene have the capacity to direct the translational positioning of histone octamers 
(Wong et al. 1997a, Guschin et al. 1998). The type of thyroid receptor recognition element present in the TR $\beta A$ promoter is a direct repeat separated by four base pairs (Glass 1994). The rotational position adopted by the TRE on the surface of the nucleosome assembled on the wild-type TR $\beta A$ gene appears optimal for continued access of the TR-RXR within chromatin. The key contacts made by the receptor with the TRE through the major groove are predicted to remain accessible from solution. The TR-RXR heterodimer is able to bind to the TRE present in the TR $\beta A$ gene in a nucleosome without significant impediment. The importance of rotational positioning for the continued capacity of TR-RXR to bind to nucleosomal DNA is shown by introducing a small $3 \mathrm{bp}$ alteration in placement of the TRE, leading to an approximate $102^{\circ}$ change in orientation with respect to the histone surface. This rotation leads to a reduction in the capacity of TR-RXR to bind to nucleosomal DNA in vitro, to a reduction in the capacity of TR-RXR to bind to polynucleosomal arrays in vivo and to a reduction in the capacity of TR-RXR to activate transcription (Wong et al. 1997a). In contrast, the manipulation of translational position of nucleosomes over the TR $\beta A$ promoter is without major consequences for TR-RXR association. Thus considerable flexibility might exist in terms of exactly where in the nucleosome the TRE is positioned for transcriptional regulation as long as the TRE is presented on the histone surface with the appropriate rotational organization.

The Xenopus TRßA promoter is influenced by an upstream enhancer containing three additional TREs, as suggested by transient transfection (Machuca et al. 1995), as well as by genomic footprinting and plasmid microinjection assays in oocytes (F D Urnov \& A P Wolffe, unpublished). Two of these TREs are spaced by $180 \mathrm{bp}$, which is sufficient to assemble a nucleosome. This type of architecture would cluster the bound thyroid hormone receptors and is likely to potentiate their activity (Fig. 6; F D Urnov, unpublished observations).

\section{Functional tests of the role of chromatin in TR-regulated transcription}

In order to understand the role of chromatin assembly in gene control by TR it is important to use an experimentally manipulatable system. The microinjection of DNA into Xenopus oocyte nuclei leads to the assembly of chromatin which can be alternately transcriptionally repressed or active (Almouzni \& Wolffe 1993, Landsberger et al. 1995,

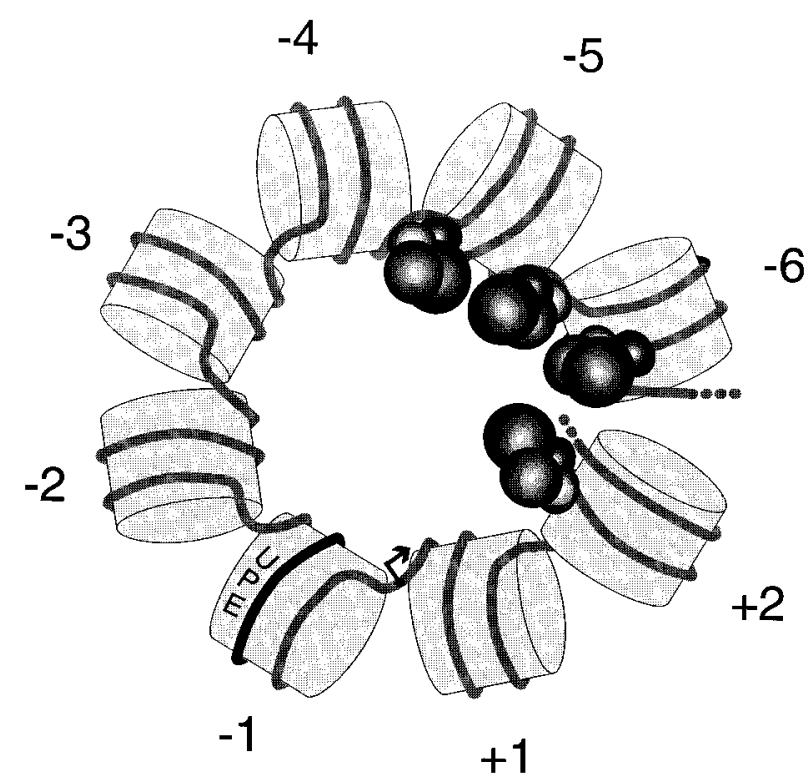

FIgURE 6. The organization of the Xenopus TR $\beta$ A promoter into a specific chromatin structure. Nucleosome positions and key recognition elements for trans-acting factors are indicated, including the upstream promoter element (UPE, Wong et al. 1997a) and binding sites for the TR-RXR heterodimer (indicated by spheres). The hooked arrow indicates the start site of transcription. Numbers indicate nucleosome positions $5^{\prime}(-)$ or $3^{\prime}(+)$ of the transcription start site.

Landsberger \& Wolffe 1995, Wong et al. 1995). These active or repressed minichromosomes provide a powerful tool to dissect transcriptional regulation in an in vivo context.

In vivo chromatin assembly normally occurs during S phase, when DNA and the histones are synthesized and when the molecular chaperones that direct the deposition of histones onto nascent DNA are maximally effective (Kaufman \& Botchan 1994, Marheineke \& Krude 1998, Wolffe 1998, Shibahar \& Stillman 1999). Microinjection of single-stranded DNA into a Xenopus oocyte nucleus leads to rapid second strand synthesis, an event to which chromatin assembly is coupled (Almouzni \& Wolffe 1993). This rapid and efficient chromatin assembly pathway leads to the repression of basal transcription in the fully assembled minichromosome. Repression occurs because the molecular mechanisms driving histone deposition outcompete those that direct the association of the basal transcriptional machinery with the promoter (Almouzni et al. 1991). The second pathway of chromatin assembly occurs when double-stranded DNA is microinjected into oocyte nuclei. This 
assembly pathway is not coupled to replication and resembles the consequence of transiently transfecting or microinjecting plasmid DNA molecules into mammalian tissue culture cells. Under these conditions chromatin assembly will still occur on the fraction of DNA that is taken up into the nucleus, but does so with much slower kinetics in a process occupying at least $4 \mathrm{~h}$ in the oocyte (which has large stores of histones) and as long as $24 \mathrm{~h}$ in a mammalian tissue culture cell (Reeves et al. 1985, Almouzni \& Wolffe 1993, Wong et al. 1998). This provides plenty of time for the basal transcriptional machinery to gain access to promoter elements and to assemble an active minichromosome.

The Xenopus laevis TR $\beta$ A promoter is transcriptionally repressed when assembled into chromatin in a replicative pathway following injection of single-stranded templates into oocyte nuclei, whereas it is active when double-stranded templates are injected. In both instances the final density of nucleosomes is equivalent, only the pathway of chromatin assembly differs (Wong et al. 1995). This illustrates the potential importance of chromatin context and assembly pathway on transcriptional control. The Xenopus oocyte lacks adequate TR to regulate transcription in a $\mathrm{T} 3$ responsive manner. However, microinjection of TR mRNA into the oocyte cytoplasm leads to TR synthesis and the acquisition of $\mathrm{T} 3$ responsive transcription. Hormonal responsiveness is greatly enhanced in the presence of the retinoid X receptor RXR, which indicates that the primary functional form of TR in the oocyte is as a heterodimer with RXR (Wong \& Shi 1995). In the absence of T3, TR-RXR will repress transcription from the active minichromosome and will further reduce transcription from the already repressed minichromosome assembled during replication (Wong et al. 1995). Consistent with these functional studies, in vivo DNase I footprinting indicates that TR-RXR will bind to a thyroid response element (TRE) in the TR $\beta A$ gene independent of the prior assembly of this element into chromatin and independent of the presence of T3 (Wong et al. 1995).

There are several unanticipated consequences of the TR-RXR binding to chromatin within the minichromosomal context. In the absence of T3 the underlying nucleosomal array with which TR-RXR is associated remains very regular upon binding of the receptors with no increase in accessibility to micrococcal nuclease (Wong et al. 1997a). This regularity is surprising because the TR-RXR generates a major site of preferential cleavage by DNase I (Wong et al. 1997a,b). We interpret these results to indicate that the unliganded TR-RXR binds to the minichromosome and functions to repress transcription within a regular nucleosomal infrastructure. With respect to the DNase I hypersensitive site, it is clear that neither disruption of a nucleosomal array nor transcriptional activity are necessary to generate such a site. We speculate that TR-RXR may recruit DNase I through protein-protein interactions much as transcriptional coactivators and corepressors might be recruited. DNase I hypersensitive sites are therefore useful markers for chromatin-bound TR and also potentially for v-ErbA bound in chromatin. Indeed, several transcriptional silencers that contain v-ErbA sites are hypersensitive to DNase I in vivo (Baniahmad et al. 1990) consistent with stable association of the $\mathrm{v}$-erbA protein, once again raising the issue of the importance of targeted chromatin remodeling for the establishment of a DNase I hypersensitive site.

On the addition of $\mathrm{T} 3$, transcriptional repression is relieved on a minichromosome generated under replication-coupled chromatin assembly conditions (injection of single-stranded template). This relief of repression leads to an apparent activation of transcription because the final transcriptional levels are more than 200 times those measured under repressed conditions (Wong et al. 1995). However, for the TR $\beta A$ gene little true activation occurs because the level of transcriptional activity in the presence of TR-RXR and T3 only approximates to that seen on chromatin templates assembled in a non-replicative pathway (injection of doublestranded template), the extended dynamic range of regulation being due to a lower level of repressed transcription. When chromatin assembly occurs through a non-replicative pathway the basal transcriptional machinery functions as if associated with naked DNA in the absence of TR-RXR. Thus the TR-RXR might regulate gene activity entirely through the establishment of a repressed transcriptional state.

It is useful to consider the physiological rationale behind unliganded receptor occupancy of target genes and concomitant repression. Unliganded TR has been implicated in maintenance of the proliferative state during vertebrate ontogeny (Bauer et al. 1998), while an important consequence of induction by $\mathrm{T} 3$ is the initiation of cell cycle arrest and differentiation (Brown et al. 1995, Tata 1996, Bauer et al. 1998). The transient immaturity of chromatin following passage of the DNA replication fork (Seale 1975, 1978) offers the opportunity for spurious activation of genes by the basal transcription machinery. Thus, in rapidly dividing cells the persistent interaction of unliganded TR with target genes required for differentiation and cell cycle arrest may represent a mechanism by 
which inappropriate gene activation during postreplicative chromatin maturation is suppressed. In this context, the ability of TR to repress transcription on partially chromatinized templates (Wong et al. 1998) may represent a useful functional feature of the receptor.

The TR-RXR remains bound to the TRE in chromatin following transcriptional activation in the presence of hormone but the underlying nucleosomal infrastructure becomes much more accessible to micrococcal nuclease (Wong et al. 1997a,b). The TRE itself is hypersensitive to DNase I digestion and additional sites of DNase I cleavage are generated in the vicinity of the promoter on addition of hormone. The increased accessibility of chromatin to nucleases in the presence of ligandbound TR is consistent with the earlier observations of Samuels et al. (1982). The important point is that the TRE remains occupied with TR-RXR when chromatin structure is disrupted and the TRßA gene becomes active (Wong et al. 1995). The continual presence of TR-RXR offers the opportunity to down-regulate transcription when hormone concentrations become limiting.

\section{The role of histone deacetylase in transcriptional repression by TR}

As we have discussed, biochemical approaches using the ligand binding domains of nuclear receptors to screen for interacting factors have identified a number of interesting proteins. The thyroid hormone receptor has the capacity to interact with diverse coactivators and corepressors in a manner which is dependent on the presence or absence of T3. In the absence of ligand, TR has been shown to interact with the corepressors NCoR (Horlein et al. 1995) and SMRT (Chen \& Evans 1995), while in the presence of ligand the receptor recruits a number of transcriptional coactivators. In addition to their recruitment by TR, NCoR and SMRT also interact with the mammalian proteins $\mathrm{mSin} 3 \mathrm{~A}$ and $\mathrm{mSin} 3 \mathrm{~B}$ that have striking homology to $S$. cerevisae Sin3p (Alland et al. 1997, Heinzel et al. 1997, Laherty et al. 1997, 1998, Nagy et al. 1997). Mammalian Sin 3 contains four paired amphipathic helices (PAH1-4). NCoR associates with the most amino terminal of these domains, PAH1. Saccharomyces cerevisiae $\operatorname{Sin} 3 p$ interacts with the histone deacetylase RPD3 (Kadosh \& Struhl 1997) and likewise the mammalian $\operatorname{Sin} 3$ proteins associate with the RPD3 homologue using contacts between the PAH3 and 4 domains (Alland et al. 1997). These interconnections suggested that TR-RXR might target transcriptional repression by recruiting histone deacetylase to modify the local chromatin environment (Wolffe 1997). However, it remained possible that components of the recruited corepressor complex such as NCoR, SMRT or Sin3 might exert repressive activities on components of the basal machinery or organize repressive chromatin structures directly without the requirement for histone deacetylase (for example, Fondell et al. 1993, Le Douarin et al. 1995). We were able to discriminate between these possibilities using the microinjection of double-stranded DNA templates into Xenopus oocyte nuclei. The slow kinetics of chromatin assembly on double-stranded DNA were especially advantageous for following the role of nucleosomes in transcriptional silencing. We found that histone deacetylase alone could repress transcription of the Xenopus TR $\beta$ A gene dependent on the assembly of a nucleosomal template (Wong et al. 1998) and that this repression could be overcome either by hormone-bound TR-RXR or by inhibition of the histone deacetylase using trichostatin $\mathrm{A}$ (TSA). Interestingly, there are distinct requirements for chromatin assembly in the establishment of transcriptional repression by the histone deacetylase alone compared with those needed in the presence of unliganded TR-RXR. The receptor can direct the repression of transcription under conditions where low levels of chromatin assembly have occurred on the template, while the deacetylase alone requires much higher levels of chromatin assembly to repress transcription. However, it is important to note that even when unliganded TR-RXR represses transcription during chromatin assembly, inhibition of histone deacetylase using Trichostatin A blocks this repression. Possible explanations for the repression of transcription by unliganded TR-RXR occurring under conditions of incomplete chromatin assembly, yet still requiring histone deacetylase include the following. (i) The active recruitment of histones to the transcriptional corepressor complex so that they are used as part of the regulatory nucleoprotein architecture to repress transcription after deacetylation (Roth et al. 1990, Edmondson et al. 1996, Wolffe \& Pruss 1996). (ii) Deacetylase may act to modify basal transcription factors and not histones (Imhof et al. 1997), generating acetylated components of the basal transcriptional machinery with enhanced functional properties. (iii) The initial process of establishing transcriptional repression might involve interactions between TR-RXR and/or the corepressor complex with the basal transcriptional machinery that might interfere with transcription initiation (Baniahmad et al. 1993, Fondell et al. 1993). This state of repression would be subsequently stabilized by other events requiring deacetylase activity, potentially including nucleosome assembly. 


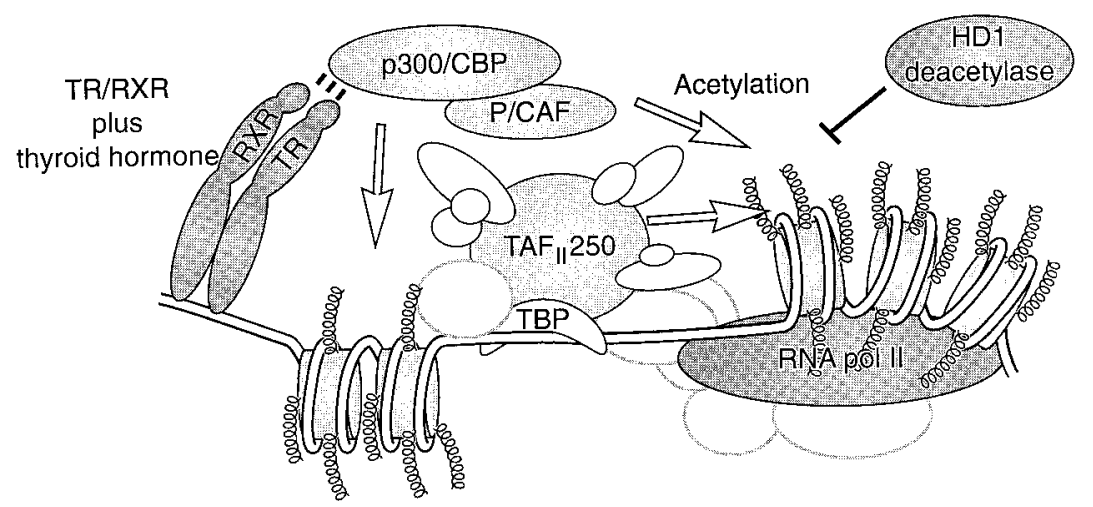

FIGURE 7. Transcriptional regulation in chromatin. Hormone-bound thyroid hormone receptor recruits a coactivator complex (p300 (CBP, $\mathrm{PCAF})$ ) that retains chromatin in an 'open' configuration and a functional transcriptional machinery associated with the promoter. This complex counteracts the continued activity of the histone deacetylase (HD1).

TAF $_{\text {II }} 250$, TATA binding protein associated factor ${ }_{\mathrm{II}} 250$.

Exactly how the unliganded TR-RXR uses histone deacetylase to repress transcription remains unclear, nevertheless the major enzymatic consequence is the targeting of deacetylase activity to the vicinity of the promoter. In the presence of ligand this situation is reversed, and histone acetyltransferases are recruited.

\section{Chromatin remodeling for transcriptional activation by TR}

A unifying feature of several of the diverse coactivator proteins described earlier is their capacity to function as histone acetyltransferases (Ogryzko et al. 1996, Yang et al. 1996, Chen et al. 1997). Thus a common theme for transcriptional activation by ligand-bound nuclear receptors is the recruitment of histone acetyltransferase activity. This recruitment might be expected to counteract the repressive influence of histone deacetylase. Consistent with this hypothesis, the addition of histone deacetylase inhibitors can relieve the requirement for transcriptional coactivators in chromatin assembled on the TR $\beta A$ promoter in Xenopus oocyte nuclei (Li et al. 1998, 1999, Wong et al. 1998). Histone acetylation states are dynamic, with the acetylated lysines of hyperacetylated histones turning over rapidly with half-lives of minutes within transcriptionally active chromatin, but much less rapidly for the hypoacetylated histones of transcriptionally silent regions (Covault \& Chalkley 1980, Zhang \& Nelson 1988). This observation implies that transcription coactivators must continually exert their acetyltransferase functions in the vicinity of a promoter (Fig. 7). The dynamics of histone acetylation provides an attractive mechanistic foundation for the reversible activation and repression of transcription.

We have discussed how the TR-RXR can bind to nucleosomal DNA to target both transcriptional repression and activation. The TR-RXR silences transcription effectively in the context of a positioned nucleosomal array (Wong et al. 1995, 1997a). On the addition of ligand this regular nucleosomal array is disrupted. The requirements for this disruption offer additional insight into the potential roles for histone acetylation and chromatin modification in gene control.

The TR-RXR alone and its recognition element are sufficient to initiate a process of chromatin disruption over an extended segment of DNA sequence as assayed by micrococcal nuclease cleavage (Wong et al. 1997a). Each TRE can target the loss of topological constraint found in three to four nucleosomes, provided the TREs are separated by at least $400 \mathrm{bp}$ of DNA. Transcription is not required for chromatin disruption and additional proximal promoter elements are necessary to facilitate hormone-dependent activation of transcription by the TR-RXR. The T3-dependent chromatin disruption depends on the AF-2 activity of the LBD. Thus we can dissect the process of gene activation by TR-RXR into at least three steps: (i) binding of the receptor to chromatin and the targeted assembly of a repressive chromatin structure; (ii) the disruption of chromatin on the addition of ligand; (iii) subsequent transcriptional activation (Wong et al. 1997b). The separation of chromatin disruption from transcription would be consistent with the opening up of a promoter from a 
repressive chromatin environment in order to facilitate the subsequent activity of the basal transcription machinery (Wolffe \& Pruss 1996). An important, yet unresolved question concerns the role of histone acetyltransferases in this disruption process. At this time, the role of transcriptional coactivators such as PCAF, p300 and SRC-1 in chromatin disruption itself has not been assayed, even though the structural and functional consequences of histone acetylation have been intensively investigated.

Chromatin disruption targeted by ligand-bound TR-RXR leads to major topological changes in minichromosomes consistent with a loss of wrapping of DNA around the histones (Bauer et al. 1994, Germond et al. 1975, Wong et al. 1997a). Although histone acetyltransferases are recruited to the ligand-bound TR-RXR, it is difficult to account for the large topological change observed through acetylation alone (Norton et al. 1989, Bauer et al. 1994). In fact, transcription can be activated without significant topological change from a TR $\beta A$ promoter complexed in chromatin with unliganded TR-RXR simply by the addition of the deacetylase inhibitor TSA (Wong et al. 1998). Thus, histone hyperacetylation in isolation seems unlikely to account for chromatin disruption. Comparable conclusions were obtained with the GR-dependent regulation of MMTV chromatin. More importantly, the chromatin disruption phenomenon in a minichromosomal context as assayed by topological change and increases in micrococcal nuclease digestion is not necessary for transcriptional activation. Whether this holds true in the case of GR-mediated transcriptional activation on the MMTV LTR remains to be determined.

Chromatin disruption as assayed by topological change and increases in micrococcal nuclease cleavage has generally been interpreted as essential for transcriptional activation (Hirschhorn et al. 1992, Imbalzano et al. 1994, Tsukiyama et al. 1994). However, transcriptional activation can occur with minimal changes in DNA topology (Pederson \& Morse 1990, Drabik et al. 1997). This would be anticipated if histone acetylation was the only alteration to chromatin structure necessary for transcriptional activation. It is possible that the pathways directing chromatin disruption in the oocyte nucleus in response to ligand-bound TR-RXR do not involve histone acetylation and that alternative means of disrupting histone-DNA contacts are employed leading to similar transcriptional consequences. Candidate mechanisms include recruitment of molecular machines such as SWI/ SNF (Coté et al. 1994, Imbalzano et al. 1994, Wang et al. 1996a,b; Fryer \& Archer 1998) or RNA polymerase itself (Wilson et al. 1996, Gaudreau et al. 1997). Chromatin disruption directed by TR-RXR might serve other purposes aside from the activation of transcription on minichromosomes. It might be necessary to destabilize higher-order chromatin structures (Hansen et al. 1991, Schwarz \& Hansen 1994). Such substantial alterations in chromatin structure, including loss of DNA wrapping in the nucleosome, might serve as an epigenetic mark for the propagation of gene activity states through replication and chromosomal duplication (Weintraub 1985), or for the recruitment of the promoter to a nuclear site competent for transcription in a true chromosomal environment (Cook 1994).

\section{CONCLUSIONS}

Nuclear receptors make very effective use of the chromatin environment to regulate transcription. As we have illustrated with the thyroid hormone and glucocorticoid receptors, their function depends upon their ability to reversibly manipulate chromatin structure towards stability or instability. These events occur dynamically within regulatory nucleoprotein architectures that can accommodate the conformational and compositional transitions induced by the receptors. Most attention in this research field is currently focused on the chromatin remodeling machines that activate or repress transcription. It is nevertheless essential to understand the structures that exist before remodeling, the remodeled state and those that are present when the gene is inactivated. Moreover, attention should be focused not only on histone-DNA interactions but also on the activities of the basal transcriptional machinery in the context of chromatin. The principal function of receptors may well be to facilitate the conversation between the basal transcriptional machinery and the chromatin environment in which it functions.

\section{REFERENCES}

Alland L, Muhle R, Hou H Jr, Potes J, Chin L, Schreiber-Agus N \& De Pinho RA 1997 Role of NCoR and histone deacetylase in Sin3-mediated transcriptional and oncogenic repression. Nature 387 49-55.

Almouzni G \& Wolffe AP 1993 Replication coupled chromatin assembly is required for the repression of basal transcription in vivo. Genes and Development 7 2033-2047.

Almouzni G, Mechali M \& Wolffe AP 1991 Transcription complex disruption caused by a transition in chromatin structure. Molecular and Cellular Biology 11 655-665.

Anzick SL, Kononen J, Walker RL, Azorsa DO, Tanner MM, Guan XY, Sauter G, Kallioniemi OP, Trent JM \& Meltzer 
PS 1997 AIB1, a steroid receptor coactivator amplified in breast and ovarian cancer. Science 277 965-968.

Archer TK, Cordingley MG, Marsaud V, Richard-Foy H \& Hager GL 1989 Steroid transactivation at a promoter organized in a specifically positioned array of nucleosomes. In Proceedings: Second International CBT Symposium on the Steroid/Thyroid Receptor Family and Gene Regulation, pp 221-238. Berlin: Birkhauser \& Verlag.

Archer TK, Cordingley MG, Wolford RG \& Hager GL 1991 Transcription factor access is mediated by accurately positioned nucleosomes on the mouse mammary tumor virus promoter. Molecular and Cellular Biology 11 688-698.

Archer TK, Lefebvre P, Wolford RG \& Hager GL 1992 Transcription factor loading on the MMTV promoter: a bimodal mechanism for promoter activation. Science $\mathbf{2 5 5}$ 1573-1576.

Arents G, Burlingame RW, Wang BW, Love WE \& Moudrianakis EN 1991 The nucleosomal core histone octamer at $3 \cdot 1 \AA$ resolution: a tripartite protein assembly and a left-handed superhelix. Proceedings of the National Academy of Sciences of the USA 88 10148-10152.

Baniahmad A, Steiner C, Kohne AC \& Renkawitz R 1990 Modular structure of a chicken lysozyme silencer involvement of an unusual thyroid-hormone receptor binding site. Cell 61 505-514.

Baniahmad A, Kohne AC \& Renkawitz R 1992 A transferable silencing domain is present in the thyroid hormone receptor, in the $\mathrm{v}$-erbA oncogene product and in the retinoic acid receptor. EMBO Fournal 11 1015-1023.

Baniahmad A, Ha I, Reinberg D, Tsai SY, Tsai MJ \& O'Malley BW 1993 Interaction of a receptor $\beta$ with transcription factor TFIIB may mediate target gene activation and derepression by thyroid hormone. Proceedings of the National Academy of Sciences of the USA 90 8832-8836.

Baniahmad A, Leng X, Burris TP, Tsai SY, Tsai M-J \& O'Malley BW 1995 The $\tau 4$ activation domain of the thyroid hormone receptor is required for release of a putative corepressor(s) necessary for transcriptional silencing. Molecular and Cellular Biology 15 76-86.

Bartsch J, Truss M, Bode J \& Beato M 1996 Moderate increase in histone acetylation activates the mouse mammary tumor virus promoter and remodels its nucleosome structure. Proceedings of the National Academy of Sciences of the USA 93 10741-10746.

Bauer A, Mikulits W, Lagger G, Stengl G, Brosch G \& Beug H 1998 The thyroid hormone receptor functions as a ligand-operated developmental switch between proliferation and differentiation of erythroid progenitors. EMBO Fournal 17 4291-4303.

Bauer WR, Hayes JJ, White JH \& Wolffe AP 1994 Nucleosome structural changes due to acetylation. Fournal of Molecular Biology 236 685-690.

Blanco JC, Minucci S, Lu J, Yang XJ, Walker KK, Chen H, Evans RM, Nakatani Y \& Ozato K 1998 The histone acetylase PCAF is a nuclear receptor coactivator. Genes and Development 12 1638-1651.

Blomquist P, Li Q \& Wrange O 1996 The affinity of nuclear factor 1 for its DNA site is drastically reduced by nucleosome organization irrespective of its rotational and translational position. Fournal of Biological Chemistry 271 154-159.

Bocquel MT, Kumar V, Stricker C, Chambon P \& Gronemeyer H 1989 The contribution of the N- and C-terminal regions of steroid receptors to activation of transcription is both receptor and cell-specific. Nucleic Acids Research 17 2581-2595.
Bresnick EH, John S, Berard DS, Lefebvre P \& Hager GL 1990 Glucocorticoid receptor-dependent disruption of a specific nucleosome on the mouse mammary tumor virus promoter is prevented by sodium butyrate. Proceedings of the National Academy of Sciences of the USA 87 3977-3981.

Bresnick EH, John S \& Hager GL 1991 Histone hyperacetylation does not alter the positioning or stability of phased nucleosomes on the mouse mammary tumor virus long terminal repeat. Biochemistry 30 3490-3497.

Bresnick EH, Bustin M, Marsaud V, Richard-Foy H \& Hager GL 1992 The transcriptionally-active MMTV promoter is depleted of H1. Nucleic Acids Research 20 273-278.

Brown DD, Wang Z, Kanamori A, Eliceiri B, Furlow JD \& Schwartzman R 1995 Amphibian metamorphosis: a complex program of gene expression changes controlled by the thyroid hormone. Recent Progress in Hormone Research 50 309-315.

Brown SA, Imbalzano AN \& Kingston RE 1996 Activatordependent regulation of transcriptional pausing on nucleosomal templates. Genes and Development 10 1479-1490.

Candau R, Chavez S \& Beato M 1996 The hormone responsive region of mouse mammary tumor virus positions a nucleosome and precludes access of nuclear factor 1 to the promoter. Fournal of Steroid Biochemistry and Molecular Biology 57 19-31.

Chakravarti D, LaMorte VJ, Nelson MC, Nakajima T, Juguilon H, Montminy M \& Evans RM 1996 Mediation of nuclear receptor signalling by CBP/p300. Nature $\mathbf{3 8 3}$ 99-103.

Chavez S \& Beato M 1997 Nucleosome-mediated synergism between transcription factors on the mouse mammary tumor virus promoter. Proceedings of the National Academy of Sciences of the USA 94 2885-2890.

Chen H, Lin RJ, Schiltz RL, Chakravarti D, Nash A, Nagy L, Privalsky ML, Nakatani Y \& Evans RM 1997 Nuclear receptor coactivator ACTR is a novel histone acetyltransferase and forms a multimeric activation complex with $\mathrm{P} / \mathrm{CAF}$ and $\mathrm{CBP} / \mathrm{p} 300$. Cell 90 569-580.

Chen JD \& Evans RM 1995 A transcriptional co-repressor that interacts with nuclear hormone receptor. Nature $\mathbf{3 7 7}$ 454-457.

Chiba H, Muramatsu M, Nomoto A \& Kato H 1994 Two human homologs of Saccharomyces cerevisiae SWI2/SNF2 and Drosophila brahma are transcriptional coactivators cooperating with the estrogen receptor and the retinoic acid receptor. Nucleic Acids Research 22 1815-1820.

Clark DJ, Hill CS, Martin SR \& Thomas JO $1988 \alpha$-Helix in the carboxy-terminal domains of histones $\mathrm{H} 1$ and $\mathrm{H} 5$. EMBO Fournal 7 69-75.

Collingwood TN, Rajanayagam $\mathrm{O}$, Adams M, Wagner R, Cavailles V, Kalkhoven E, Matthews C, Nystrom E, Stenlof K, Lindstedt G, Tisell L, Fletterick RJ, Parker MG \& Chatterjee VK 1997 A natural transactivation mutation in the thyroid hormone beta receptor: impaired interaction with putative transcriptional mediators. Proceedings of the National Academy of Sciences of the USA 94 248-253.

Collingwood TN, Wagner R, Matthews CH, Clifton-Bligh RJ, Gurnell M, Rajanayagam O, Agostini M, Fletterick RJ, Beck-Peccoz P, Reinhardt W, Binder G, Ranke MB, Hermus A, Hesch RD, Lazarus J, Newrick P, Parfitt V, Raggatt P, de Zegher F \& Chatterjee VK 1998 A role for helix 3 of the TR $\beta$ ligand-binding domain in coactivator recruitment identified by characterization of a third cluster of mutations in resistance to thyroid hormone. EMBO Fournal 17 4760-4770.

Cook PR 1994 RNA polymerase: structural determinant of the chromatin loop and the chromosome. BioEssays $\mathbf{1 6}$ $425-430$. 
Coté J, Quinn J, Workman JL \& Peterson CL 1994 Stimulation of GAL4 derivative binding to nucleosomal DNA by the yeast SWI/SNF complex. Science $\mathbf{2 6 5}$ 53-60.

Covault J \& Chalkley R 1980 The identification of distinct populations of acetylated histone. Fournal of Biological Chemistry 255 9110-9116.

Dallas PB, Cheney IW, Liao D-W, Bowrin V, Byam W, Pacchione S, Kobayashi R, Yaciuk P \& Moran E 1998 p300/CREB binding protein-related p270 is a component of mammalian SWI/SNF complexes. Molecular and Cellular Biology 18 3596-3603.

Darimont BD, Wagner RL, Apriletti JW, Stallcup MR, Kushner PJ, Baxter JD, Fletterick RJ \& Yamamoto KR 1998 Structure and specificity of nuclear receptor-coactivator interactions. Genes and Development 12 3343-3356.

Drabik CE, Nicita CA \& Lutter LC 1997 Measurement of linker number change in transcribing chromatin. Fournal of Molecular Biology 267 794-806.

Edmondson DG, Smith MM \& Roth SY 1996 Repression domain of the yeast global repressor Tup1 interacts directly with histones $\mathrm{H} 3$ and $\mathrm{H} 4$. Genes and Development 10 1247-1259.

Elfring LK, Daniel C, Papoulas O, Deuring R, Sarte M, Moseley S, Beek SJ, Waldrip WR, Daubress G, DePace A, Kennison JA \& Tamkun JW 1998 Genetic analysis of brahma: the Drosophila homolog of the yeast chromatin remodeling factor SWI2/SNF2. Genetics 148 251-265.

Feng W, Ribeiro RCJ, Wagner RL, Nguyen H, Apriletti JW, Fletterick RJ, Baxter JD, Kushner PJ \& West BL 1998 Hormone-dependent coactivator binding to a hydrophobic cleft on nuclear receptors. Science 280 1747-1749.

Fondell JD, Roy AL \& Roeder RG 1993 Unliganded thyroid hormone receptor inhibits formation of a functional preinitiation complex: implications for active repression. Genes and Development 7 1400-1410.

Fragoso G, John S, Robertis S \& Hager GL 1995 Nucleosome positioning on the MMTV LTR from the frequently-biased occupancy of multiple frames. Genes and Development 9 1933-1947.

Fryer CJ \& Archer TK 1998 Chromatin remodeling by the glucocorticoid receptor requires the BRG1 complex. Nature 393 88-91.

Gaudreau L, Schmid A, Blaschke D, Ptashne M \& Horz W 1997 RNA polymerase II holoenzyme recruitment is sufficient to remodel chromatin at the yeast PHO5 promoter. Cell 89 55-62.

Germond JE, Hirt B, Oudet P, Gross-Bellard M \& Chambon P 1975 Folding of the double helix in chromatin like structures from simian virus 40. Proceedings of the National Academy of Sciences of the USA 72 1843-1847.

Glass CK 1994 Differential recognition of target genes by nuclear receptor monomers, dimers, and heterodimers. Endocrine Reviews 15 391-407.

Godde JS, Nakatani Y \& Wolffe AP 1995 The amino-terminal tails of the core histones and the translational position of the TATA box determine TBP/TFIIA association with nucleosomal DNA. Nucleic Acids Research 23 4557-4564.

Guschin D, Chandler S \& Wolffe AP 1998 Asymmetric linker histone association directs the asymmetric rearrangement of core histone interactions in a positioned nucleosome containing a thyroid hormone response element. Biochemistry 37 8629-8636.

Hansen JC \& Wolffe AP 1992 Chromatin folding inhibits both transcription initiation and elongation by RNA polymerase III. Biochemistry 31 7977-7988.

Hansen JC \& Wolffe AP 1994 A role for histones H2A/H2B in chromatin folding and transcriptional repression. Proceedings of the National Academy of Sciences of the USA 91 2339-2343.

Hansen JC, van Holde KE \& Lohr D 1991 The mechanism of nucleosome assembly onto oligomers of the sea urchin $5 \mathrm{~S}$ DNA positioning sequence. Fournal of Biological Chemistry 266 4276-4282.

Hansen JC, Tse C \& Wolffe AP 1998 Structure and function of the core histone $\mathrm{N}$-termini: more than meets the eye. Biochemistry 37 17637-17641.

Hanstein B, Eckner R, DiRenzo J, Halachmi S, Liu H, Searoy B, Kurokawa R \& Brown M 1996 p300 is a component of an estrogen receptor coactivator complex. Proceedings of the National Academy of Sciences of the USA 93 11540-11545.

Heery DM, Kalkhoven E, Hoare S \& Parker MG 1997 A signature motif in transcriptional co-activators mediates binding to nuclear receptors. Nature 387 733-736.

Heinzel T, Laviusky RM, Mullen TM, Soderstrom M, Laherty CD, Torchia JT, Yang W-M, Brard C, Ngo SG, Davie JR, Seto E, Eisenman RM, Rose DW, Glass CK \& Rosenfeld MG 1997 N-CoR, mSIN3, and histone deacetylase in a complex required for repression by nuclear receptors and Mad. Nature 387 43-48.

Hill CS, Rimmer JM, Green BN, Finch JT \& Thomas JO 1991 Histone-DNA interactions and their modulation by phosphorylation of Ser-Pro-X-Lys/Arg-motifs. EMBO Fournal 10 1939-1948.

Hirschhorn JN, Brown SA, Clark CD \& Winston F 1992 Evidence that SNF2/SWI2 and SNF activate transcription in yeast by altering chromatin structure. Genes and Development 6 2288-2298.

Hong H, Kohli K, Trivedi A, Johnson DL \& Stallcup MR 1996 GRIP1, a novel mouse protein that serves as a transcriptional coactivator in yeast for the hormone binding domains of steroid receptors. Proceedings of the National Academy of Sciences of the USA 93 4948-4952.

Hong L, Schroth GP, Matthews HR, Yau P \& Bradbury EM 1993. Studies of the DNA binding properties of the histone H4 amino terminus. Fournal of Biological Chemistry 268 305-314.

Horlein AJ, Naar AM, Heinzel T, Torchia J, Gloss B, Kurokawa R, Ryan A, Kamei Y, Soderstrom M, Glass CK \& Rosenfeld MG 1995 Ligand-independent repression by the thyroid hormone receptor mediated by a nuclear receptor co-repressor. Nature 377 397-404.

Imbalzano AM, Kwon H, Green MR \& Kingston RE 1994 Facilitated binding of TATA-binding protein to nucleosomal DNA. Nature 370 481-485.

Imhof A, Yang XJ, Ogryzko VV, Nakatani Y, Wolffe AP \& Ge H 1997 Acetylation of general transcription factors by histone acetyltransferases: identification of a major site of acetylation in TFIIE $\beta$. Current Biology 7 689-692.

Jackson TA, Richer JK, Bain DL, Takimoto GS, Tung L \& Horwitz KB 1997 The partial agonist activity of antagonistoccupied steroid receptors is controlled by a novel hinge domain-binding coactivator L7/SPA and the corepressors N-CoR or SMRT. Molecular Endocrinology 11 693-705.

Kadosh D \& Struhl K 1997 Repression by Ume6 involves recruitment of a complex containing $\operatorname{Sin} 3$ corepressor and Rpd3 histone deacetylase to target promoters. Cell $\mathbf{8 9}$ 365-371.

Kamei Y, Xu L, Heinzel T, Torchia J, Kurokama R, Gloss B, Lin S-C, Heyman RA, Rose DW, Glass CK \& Rosenfeld MG 1996 A CBP integrator complex mediates transcriptional activation and AP-1 inhibition by nuclear receptors. Cell 85 403-414. 
Kaufmann PD \& Botchan MR 1994 Assembly of nucleosomes: do multiple assembly factors mean multiple mechanisms? Current Opinion in Genetics and Development 4 229-235.

Kennison JA \& Tamkun JW 1988 Dosage-dependent modifiers of Polycomb and Antennapedia mutations in Drosophila. Proceedings of the National Academy of Sciences of the USA 85 8136-8140.

Korzus E, Torchia J, Rose DW, Xu L, Kurokawa R, McInerney E, Mullen R-M, Glass CK \& Rosenfeld MG 1998 Transcription factor-specific requirements for coactivators and their acetyltransferase functions. Science $\mathbf{2 7 9}$ 703-707.

Kruger W, Peterson CL, Sil A, Coburn C, Arents G, Moudrianakis EN \& Herskowitz I 1995 Amino acid substitutions in the structured domains of histones $\mathrm{H} 3$ and $\mathrm{H} 4$ partially relieve the requirement of the yeast SWI/SNF complex for transcription. Genes and Development 9 $2770-2779$.

Kurokawa R, Soderstrom M, Horlein A, Halachmi S, Brown M, Rosenfeld MG \& Glass CK 1995 Polarity-specific activities of retinoic acid receptors determined by a corepressor. Nature 377 451-454.

Kurumizaka H \& Wolffe AP 1997 Sin mutations of histone H3: influence on nucleosome core structure and function. Molecular and Cellular Biology 17 6953-6969.

Laherty CD, Yang WM, Sun JM, Davie JR, Seto E \& Eisenman RM 1997 Histone deacetylase associated with the $\mathrm{mSin} 3$ corepressor mediates Mad transcriptional repression. Cell 89 349-356.

Laherty CD, Billin AN, Lavinsky RM, Yochum GS, Bush AC, Sun JM, Mullen TM, Davie JR, Rose DW, Glass CK, Rosenfeld MG, Ayer DE \& Eisenman RN 1998 Sap30, a component of the mSin 3 corepressor complex involved in $\mathrm{N}$-CoR-mediated repression by specific transcription factors. Molecular Cell 2 33-42.

Landsberger N \& Wolffe AP 1995 The role of chromatin and Xenopus heat shock transcription factor (XHSF1) in the regulation of the Xenopus hsp70 promoter in vivo. Molecular and Cellular Biology 15 6013-6024.

Landsberger N, Ranjan M, Almouzni G, Stump D \& Wolffe AP 1995 The heat shock response in Xenopus oocytes, embryos and somatic cells: a regulatory role for chromatin. Developmental Biology 170 62-74.

Lavinsky RM, Jepsen K, Heinzel T, Torchia J, Mullen TM, Schiff R, Del-Rio AL, Ricote M, Ngo S, Gemsch J, Hilsenbeck SG, Osborne CK, Glass CK, Rosenfeld MG \& Rose DW 1998 Diverse signaling pathways modulate nuclear receptor recruitment of N-CoR and SMRT complexes. Proceedings of the National Academy of Sciences of the USA 95 2920-2925.

Le Douarin B, Zechel C, Garnier J-M, Lutz Y, Tora L, Pierrat B \& Heery D 1995 The N-terminal part of TIF1, a putative mediator of the ligand-dependent activation function $(\mathrm{AF}-2)$ of nuclear receptors, is fused to B-raf in the oncogenic protein T18. EMBO Fournal 14 2020-2033.

Le Douarin B, Nielsen AL, Garnier JM, Ichinose H, Jeanmougin F, Losson R \& Chambon P 1996 A possible involvement of TIF1 alpha and TIF1 beta in the epigenetic control of transcription by nuclear receptors. EMBO Fournal 15 6701-6715.

Le Douarin B, You J, Nielsen AL, Chambon P \& Losson R 1998 TIF1 $\alpha$ : a possible link between KRAB zinc finger proteins and nuclear receptors. Fournal of Steroid Biochemistry and Molecular Biology 65 43-50.

Lee DY, Hayes JJ, Pruss D \& Wolffe AP 1993 A positive role for histone acetylation in transcription factor binding to nucleosomal DNA. Cell 72 73-84.
Lee HH \& Archer TK 1994 Nucleosome-mediated disruption of transcription factor-chromatin initiation complexes at the mouse mammary tumor virus long terminal repeat in vivo. Molecular and Cellular Biology 14 32-41.

Lee HL \& Archer TK 1998 Prolonged glucocorticoid exposure dephosphorylates histone $\mathrm{H} 1$ and inactivates the MMTV promoter. EMBO fournal 17 1454-1466.

Lee JW, Choi HS, Gyuris J, Brent R \& Moore DD 1995 Two classes of proteins dependent on either the presence or absence of thyroid hormone for interaction with the thyroid hormone receptor. Molecular Endocrinology 9 243-254.

Lefebvre D, Mouchon A, Lefebvre B \& Formstecher P 1998 Binding of retinoic acid receptor heterodimers to DNA - role for histones NH2 termini. Fournal of Biological Chemistry 273 12288-12295.

Li G, Chandler SP, Wolffe AP \& Hall TC 1998 Architectural specificity in chromatin structure at the TATA box in vivo: nucleosome displacement upon $\beta$-phaseolin gene activation. Proceedings of the National Academy of Sciences of the USA $954772-4777$.

Li H, Gomes PJ \& Chen JD 1997 RAC3, a steroid/nuclear receptor-associated coactivator that is related to SRC-1 and TIF2. Proceedings of the National Academy of Sciences of the USA 94 8479-8484.

Li Q \& Wrange O 1993 Translational positioning of a nucleosomal glucocorticoid response element modulates glucocorticoid receptor affinity. Genes and Developmental 7 2471-2482.

Li Q \& Wrange O 1995 The accessibility of a glucocorticoid response element dependent on its rotational positioning. Molecular and Cellular Biology 15 4375-4384.

Li Q, Herrler M, Landsberger N, Kaludov N, Ogrzyko VV, Nakatani Y \& Wolffe AP 1998 Xenopus NF-Y pre-sets chromatin and potentiates acetylation responsive transcription from the Xenopus hsp70 promoter in vivo. EMBO fournal 17 6300-6315.

Li Q, Imhof A, Collingwood TN, Urnov FD \& Wolffe AP 1999 p300 stimulates transcription instigated by ligandbound thyroid hormone receptor at a step subsequent to chromatin disruption. EMBO fournal (In Press).

Lin BC, Hong S-H, Krig S, Yoh SM \& Privalsky ML 1997 A conformational switch in nuclear hormone receptors is involved in coupling hormone binding to corepressor release. Molecular and Cellular Biology 17 6131-6138.

Luger K, Mader AW, Richmond RK, Sargent DF \& Richmond TJ 1997 X-ray structure of the nucleosome core

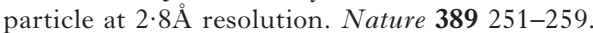

Luisi BF, Xu WX, Otwinowski Z, Freedman LP, Yamamoto KR \& Sigler P 1991 Crystallographic analysis of the interaction of the glucocorticoid receptor with DNA. Nature 352 497-502.

Machuca I, Esslemont G, Fairclough L \& Tata JR 1995 Analysis of structure and expression of the Xenopus thyroid hormone receptor $\beta$ gene to explain its autoregulation. Molecular Endocrinology 9 96-107.

McInerney EM, Rose DW, Flynn SE, Westin S, Mullen TM, Krones A, Inostroza J, Torchia J, Nolte RT, Assa-Munt N, Milburn MV, Glass CK \& Rosenfeld MG 1998 Determinants of coactivator LXXLL motif specificity in nuclear receptor transcriptional activation. Genes and Development 12 3357-3368.

McKenna NJ, Nawaz Z, Tsai SY, Tsai M-Y \& O’Malley BW 1998 Distinct steady-state nuclear receptor coregulators complexes exist in vivo. Proceedings of the National Academy of Sciences of the USA 95 11697-11702.

Marheineke K \& Krude T 1998 Nucleosome assembly activity and intracellular localization of human CAF-1 changes 
during the cell division cycle. Fournal of Biological Chemistry 273 15279-15286.

Meersseman G, Pennings S \& Bradbury EM 1992 Mobile nucleosomes - a general behavior. EMBO Fournal 11 2951-2959.

Meyer M-E, Gronemeyer H, Turcotte B, Bocquel M-T, Tasset D \& Chambon P 1989 Steroid hormone receptors compete for factors that mediate their enhancer function. Cell $\mathbf{5 7}$ $433-442$.

Morse RH 1989 Nucleosomes inhibit both transcriptional initiation and elongation by RNA polymerase III in vitro. EMBO Fournal 8 2343-2351.

Muchardt C \& Yaniv M 1993 A human homolog of Saccharomyces cerevisiae SNF2/SWI2 and Drosophila brm genes potentiates transcriptional activation by the glucocorticoid receptor. EMBO Fournal 12 4279-4290.

Nagy L, Kao HY, Chakravarti D, Lin RJ, Hassig CA, Ayer DE, Schreiber SL \& Evans RM 1997 Nuclear receptor repression mediated by a complex containing SMRT, mSin3A, and histone deacetylase. Cell 89 373-380.

Neigeborn L \& Carlson M 1984 Genes affecting the regulation of SUC2 gene repression in Saccharomyces cerevisiae. Genetics 108 845-858.

Nightingale KP, Wellinger RE, Sogo JM \& Becker PB 1998 Histone acetylation facilitates RNA polymerase II transcription of the Drosophila hsp26 gene in chromatin. EMBO Fournal 17 2865-2876.

Nolte RT, Wisely GB, Westin S, Cobbs JE, Lambert MH, Kurokawa R, Rosenfeld MG, Willson TM, Glass CK \& Milburn MV 1998 Ligand binding and coactivator assembly of the peroxisome proliferator-activated receptor- $\gamma$. Nature 395 137-143.

Norton VG, Imai BS, Yau P \& Bradbury EM 1989 Histone acetylation reduces nucleosome core particle linking number change. Cell 57 449-457.

Ogryzko VV, Schiltz RL, Russanova V, Howard BH \& Nakatani Y 1996 The transcriptional coactivators p300 and CBP are histone acetyltransferases. Cell 87 953-959.

Onate SA, Tsai SY, Tsai M-J \& O’Malley BW 1995 Sequence and characterization of a coactivator for the steroid hormone receptor superfamily. Science 270 1354-1357.

Ordentlich P, Downes M, Xie W, Genin A, Spinner NB \& Evans RM 1999 Unique forms of human and mouse nuclear receptor corepressor SMRT. Proceedings of the National Academy of Sciences of the USA 96 2639-2644.

Ostlund Farrants AK, Blomquist P, Kwon H \& Wrange O 1997 Glucocorticoid receptor-glucocorticoid response element binding stimulates nucleosome disruption by the SWI/SNF complex. Molecular and Cellular Biology 17 895-905.

Papoulas O, Beek SJ, Moseley SL, McCallum CM, Sarte M, Shearn A \& Tamkun JW 1998 The Drosophila trithorax group proteins BRM, ASH1, and ASH2 are subunits of distinct protein complexes. Development 125 3955-3966.

Patterton HG \& Simpson RT 1994 Nucleosomal location of the STE6 TATA box and Mata2p-mediated repression. Molecular and Cellular Biology 14 4002-4010.

Pederson DS \& Morse RH 1990 Effect of transcription of yeast chromatin on DNA topology in vivo. EMBO Fournal 9 1873-1881.

Perlmann T \& Wrange O 1988 Specific glucocorticoid receptor binding to DNA reconstituted in a nucleosome. $E M B O$ Fournal 7 3073-3083.

Perlmann T \& Wrange O 1991 Inhibition of chromatin assembly in Xenopus oocytes correlates with derepression of the mouse mammary tumor virus promoter. Molecular and Cellular Biology 11 5259-5265.
Peterson CL, Dingwall A \& Scott MP 1994 SWI/SNF gene products are components of a large multisubunit complex required for transcriptional enhancement. Proceedings of the National Academy of Sciences of the USA 91 2905-2908.

Pina B, Barettino D, Truss M \& Beato M $1990 a$ Structural features of a regulatory nucleosome. Fournal of Molecular Biology 216 975-990.

Pina B, Bruggemeier U \& Beato M $1990 b$ Nucleosome positioning modulates accessibility of regulatory proteins to the mouse mammary tumor virus promoter. Cell 60 719-731.

Pruss D, Bartholomew B, Persinger J, Hayes J, Arents G, Moudrianakis EN \& Wolffe AP 1996 An asymmetric model for the nucleosome: a binding site for linker histones inside the DNA gyres. Science 274 614-617.

Ranjan M, Wong J \& Shi Y-B 1994 Transcriptional repression of Xenopus TR $\beta$ gene is mediated by a thyroid hormone response element located near the start site. Fournal of Biological Chemistry 269 24699-24705.

Reeves R, Gorman CM \& Howard B 1985 Minichromosome assembly of non-integrated plasmid DNA transfected into mammalian cells. Nucleic Acids Research 13 3599-3615.

Richard-Foy H \& Hager GL 1987 Sequence-specific positioning of nucleosomes over the steroid-inducible MMTV promoter. EMBO Fournal 6 2321-2328.

Roberts MS, Fragoso G \& Hager GL 1995 The MMTV LTR $\mathrm{B}$ nucleosome adopts multiple translational and rotational positions during in vitro reconstitution. Biochemistry 34 12470-12480.

Roth SY, Dean A \& Simpson RT 1990 Yeast $\alpha 2$ repressor positions nucleosomes in TRP1/ARS1 chromatin. Molecular and Cellular Biology 10 2247-2260.

Samuels HH, Perlman AJ, Raaka BM \& Stanley F 1982 Organization of the thyroid hormone receptor in chromatin. Recent Progress in Hormone Research 38 557-599.

Schild C, Claret F-X, Wahli W \& Wollfe AP 1993 A nucleosome-dependent static loop potentiates estrogenregulated transcription from the Xenopus vitellogenin B1 promoter in vitro. EMBO Fournal 12 423-433.

Schwarz PM \& Hansen JC 1994 Formation and stability of higher order chromatin structures. Contributions of the histone octamer. Fournal of Biological Chemistry 269 16284-16298.

Seale RL 1975 Assembly of DNA and protein during replication in HeLa cells. Nature 255 247-249.

Seale RL 1978 Nucleosomes associated with newly replicated DNA have an altered conformation. Proceedings of the National Academy of Sciences of the USA 75 2717-2721.

Shi Y-B, Yaoita Y \& Brown DD 1992 The earliest changes in gene expression in tadpole intestine induced by thyroid hormone. Fournal of Biological Chemistry 268 20312-20317.

Shibahar K \& Stillman B 1999 Replication-dependent marking of DNA of PCNA facilitates CAF-1 coupled inheritance of chromatin. Cell 96 575-585.

Smith CL, Onate SA, Tsai M-J \& O'Malley BW 1996 CREBbinding protein acts synergistically with steroid receptor coactivator-1 to enhance steroid receptor-dependent transcription. Proceedings of the National Academy of Sciences of the USA 93 8884-8888.

Smith CL, Nawaz Z \& O'Malley BW 1997 Coactivator and corepressor regulation of the agonist/antagonist activity of the mixed antiestrogen, 4-hydroxytamoxifen. Molecular Endocrinology 11 657-666.

Spencer TE, Jenster G, Burcin MM, Allis CD, Zhou J, Mizzen CA, Mizzen CA, McKenna NJ, Onate SA, Tsai SY, Tsai MJ \& O'Malley BW 1997 Steroid receptor coactivator-1 is a histone acetyltransferase. Nature 389 194-198. 
Stern MJ, Jensen RE \& Herskowitz I 1984 Five SWI genes are required for expression of the $\mathrm{HO}$ gene in yeast. Fournal of Molecular Biology 178 853-868.

Szilak L, Moitra J, Krylov D \& Vinson C 1997 Phosphorylation destabilizes $\alpha$-helices. Nature Structural Biology 4 112-114.

Takeshita A, Cardona GR, Koibuchi N, Suen CS \& Chin WW 1997 TRAM-1, a novel $160 \mathrm{kDa}$ thyroid hormone receptor activator molecule, exhibits distinct properties from steroid receptor coactivator-1. Fournal of Biological Chemistry 272 27629-27634.

Tamkun JW, Deuring R, Scott MP, Kissinger M, Patlatucci AM, Kaufman TC \& Kennison JA 1992 Brahma: a regulator of Drosophila homeotic genes structurally related to the yeast transcriptional activator SNF2/SWI2. Cell 68 561-572.

Tata JR 1996 Metamorphosis: an exquisite model for hormonal regulation of post-embryonic development. Biochemical Society Symposium 62 123-136.

Torchia J, Rose DW, Inostroza J, Kamei Y, Westin S, Glass CK \& Rosenfeld MG 1997 The transcriptional co-activator $\mathrm{p} / \mathrm{CIP}$ binds CBP and mediates nuclear-receptor function. Nature 387 677-684.

Torchia J, Glass C \& Rosenfeld M 1998 Co-activators and co-repressors in the integration of transcriptional responses. Current Opinion in Cell Biology 10 373-383.

Truss M, Bartsch J, Schelbert A, Haché RJG \& Beato M 1995 Hormone induces binding of receptors and transcription factors to a rearranged nucleosome on the MMTV promoter in vivo. EMBO Fournal 14 1737-1751.

Tse C, Sera T, Wolffe AP \& Hansen JC 1998 Disruption of higher order folding by core histone acetylation dramatically enhances transcription of nucleosomal arrays by RNA polymerase III. Molecular and Cellular Biology 18 4629-4638.

Tsukiyama T, Becker PB \& Wu C 1994 ATP-dependent nucleosome disruption at a heat-shock promoter mediated by binding of GAGA transcription factor. Nature 367 $525-532$.

Ura K, Hayes JJ \& Wolffe AP 1995 A positive role for nucleosome mobility in the transcriptional activity of chromatin templates: restriction by linker histones. EMBO Fournal 14 $3752-3765$

Ura K, Kurumizaka H, Dimitrov S, Almouzni G \& Wolffe AP 1997 Histone acetylation: influence on transcription by RNA polymerase, nucleosome mobility and positioning, and linker histone dependent transcriptional repression. EMBO fournal 16 2096-2107.

Voegel JJ, Heine MJS, Zechel C, Chambon P \& Gronemeyer H 1996 TIF2, a $160 \mathrm{kDa}$ transcription mediator for the ligand-dependent activation function $\mathrm{AF}-2$ of nuclear receptors. EMBO fournal 15 3667-3675.

Vom Baur E, Zechel C, Heery D, Heine MJ, Garnier JM, Vivat V, Le Douarin B, Gronemeyer H, Chambon P \& Losson R 1996 Differential ligand-dependent interactions between the AF-2 activating domain of nuclear receptors and the putative transcriptional intermediary factors mSUG1 and TIF1. EMBO Fournal 15 110-124.

Wade PA, Pruss D \& Wolffe AP 1997 Histone acetylation: chromatin in action. Trends in Biochemical Sciences 22 128-132.

Wang W, Côté J, Xue Y, Zhou S, Khavara PA, Biggar SR, Muchardt C, Kalpana GV, Goff SP, Yaniv M, Workman JL \& Crabtree GR $1996 a$ Purification and biochemical heterogeneity of the mammalian SWI/SNF complex. EMBO fournal 15 5370-5382.

Wang W, Xue Y, Zhou S, Kuo A, Cairns BR \& Crabtree GR $1996 b$ Diversity and specialization of mammalian SWI/SNF complexes. Genes and Development 10 2117-2130.
Weintraub H 1985 Assembly and propagation of repressed and derepressed chromosomal states. Cell 42 705-711.

Weschser MA, Kladde MP, Alfieri JA \& Peterson CL 1997 Effects of Sin versions of histone $\mathrm{H} 4$ on yeast chromatin structure and function. EMBO Fournal 16 2086-2095.

Westin S, Kurokawa R, Nolte RT, Wisely GB, McInerney EI, Rose DW, Milburn MV, Rosenfeld MG \& Glass CK 1998 Interactions controlling the assembly of nuclearreceptor heterodimers and co-activators. Nature 395 199-202.

Wilson CJ, Chao DM, Imbalzano AN, Schnitzer GR, Kingston R \& Young RA 1996 RNA polymerase II holoenzyme contains SWI/SNF regulators involved in chromatin remodeling. Cell 84 235-244.

Wolffe AP 1997 Sinful repression. Nature 387 16-17.

Wolffe AP 1998 Chromatin Structure and Function, 3rd edn. London: Academic Press.

Wolffe AP \& Pruss D 1996 Targeting chromatin disruption: transcription regulators that acetylate histones. Cell $\mathbf{8 4}$ $817-819$

Wolffe AP, Khochbin S \& Dimitrov S 1997 What do linker histones do in chromatin? BioEssays 19 249-255.

Wong C-W \& Privalsky ML 1998 Transcriptional repression by the SMRT-mSin 3 corepressor: multiple interactions, multiple mechanisms, and a potential role for TFIIB. Molecular and Cellular Biology 18 5500-5510.

Wong J \& Shi Y-B 1995 Coordinated regulation of and transcriptional activation by Xenopus thyroid hormone and retinoid X receptors. Fournal of Biological Chemistry 270 18479-18483

Wong J, Shi Y-B \& Wolffe AP 1995 A role for nucleosome assembly in both silencing and activation of the Xenopus TR $\beta A$ gene by the thyroid hormone receptor. Genes and Development 9 2696-2711.

Wong J, Li Q, Levi B-Z, Shi Y-B \& Wolffe AP $1997 a$ Structural and functional features of a specific nucleosome containing a recognition element for the thyroid hormone receptor. EMBO Fournal 16 7130-7145.

Wong J, Shi Y-B \& Wolffe AP $1997 b$ Determinants of chromatin disruption and transcriptional regulation instigated by the thyroid hormone receptor: hormone regulated chromatin disruption is not sufficient for transcriptional activation. EMBO Fournal 16 3158-3171.

Wong J, Patterton D, Imhof A, Shi Y-B \& Wolffe AP 1998 Distinct requirements for chromatin assembly in transcriptional repression by thyroid hormone receptor and histone deacetylase. EMBO Fournal 17 520-534.

Yang X-J, Ogryzko VV, Nishikawa J-I, Howard B \& Nakatani Y 1996 A p300/CBP-associated factor that competes with the adenoviral E1A oncoprotein. Nature 32 319-324.

Yaoita Y \& Brown DD 1990 A correlation of thyroid hormone receptor gene expression with amphibian metamorphosis. Genes and Development 4 1917-1924.

Yoshinaga SK, Peterson SL, Herskowitz I \& Yamamoto KR 1992 Roles of SWI1, SWI2 and SWI3 proteins for transcriptional enhancement by steroid receptors. Science 258 1598-1604.

Zamir I, Dawson J, Lavinsky RM, Glass CK, Rosenfeld MG \& Lazar MA 1997 Cloning and characterization of a corepressor and potential component of the nuclear hormone receptor repression complex. Proceedings of the National Academy of Sciences of the USA 94 14400-14405.

Zaret KS \& Yamamoto KR 1984 Reversible and persistent changes in chromatin structure accompany activation of a glucocorticoid dependent enhancer element. Cell 38 29-38.

Zhang D-E \& Nelson DA 1988 Histone acetylation in chicken erythrocytes. Rates of acetylation and evidence that histones 
in both active and potentially active chromatin are rapidly modified. Biochemical Fournal 250 233-240.

Zhang W, Bone JR, Edmondson DG, Turner BM \& Roth SY 1998 Essential and redundant functions of histone acetylation revealed by mutation of target lysines and loss of the Gcn5p acetyltransferase. EMBO Fournal 17 3155-3167.
Zhao K, Wang W, Rando OJ, Xue Y, Swiderek K, Kuo A \& Crabtree GR 1998 Rapid and phosphoinositol-dependent binding of the SWI/SNF-like BAF complex to chromatin after T lymphocyte receptor signalling. Cell 95 625-636.

RECEIVED 12 May 1999 